\title{
Zerumbone Modulates
}

\section{$\alpha_{2 A}$-Adrenergic, TRPV1, and NMDA NR2B Receptors Plasticity in CCl-Induced Neuropathic Pain In Vivo and LPS-Induced SH-SY5Y Neuroblastoma In Vitro Models}

\section{OPEN ACCESS}

Edited by:

Adriana Gibara Guimarães,

Federal University of Sergipe,

Brazil

Reviewed by: Thallita Kelly Rabelo, Federal University of Sergipe,

Ernest Jennings, James Cook University,

Australia

${ }^{*}$ Correspondence: Enoch Kumar Perimal enoch@upm.edu.my; enoch.perimal@adelaide.edu.au

Specialty section: This article was submitted to Neuropharmacology,

a section of the journal

Frontiers in Pharmacology

Received: 24 September 2019 Accepted: 27 January 2020 Published: 04 March 2020

Citation:

Chia JSM, Izham NAM, Farouk AAO,

Sulaiman MR, Mustafa S, Hutchinson MR and Perimal EK (2020)

Zerumbone Modulates $\alpha_{2 A}$ Adrenergic, TRPV1, and NMDA NR2B Receptors Plasticity in CCl-Induced Neuropathic Pain In Vivo and LPSInduced SH-SY5Y Neuroblastoma In Vitro Models.

Front. Pharmacol. 11:92. doi: 10.3389/fphar.2020.00092

\author{
Jasmine Siew Min Chia ${ }^{1,2}$, Noor Aishah Mohammed Izham ${ }^{1}$, Ahmad Akira Omar Farouk ${ }^{1}$, \\ Mohd Roslan Sulaiman ${ }^{1}$, Sanam Mustafa ${ }^{3}$, Mark R. Hutchinson ${ }^{4}$ \\ and Enoch Kumar Perimal ${ }^{1,4 *}$ \\ ${ }^{1}$ Department of Biomedical Science, Faculty of Medicine and Health Sciences, Universiti Putra Malaysia, Serdang, Malaysia, \\ ${ }^{2}$ Centre for Community Health Studies, Faculty of Health Sciences, Universiti Kebangsaan Malaysia, Kuala Lumpur, \\ Malaysia, ${ }^{3}$ Faculty of Health and Medical Sciences, University of Adelaide, Adelaide, SA, Australia, ${ }^{4}$ Australian Research \\ Council Centre of Excellence for Nanoscale BioPhotonics, University of Adelaide, Adelaide, SA, Australia
}

Zerumbone has shown great potential in various pathophysiological models of diseases, particularly in neuropathic pain conditions. Further understanding the mechanisms of action is important to develop zerumbone as a potential anti-nociceptive agent. Numerous receptors and pathways function to inhibit and modulate transmission of pain signals. Previously, we demonstrated involvement of the serotonergic system in zerumbone's antineuropathic effects. The present study was conducted to determine zerumbone's modulatory potential involving noradrenergic, transient receptor potential vanilloid type 1 (TRPV1) and N-methyl-D-aspartate (NMDA) receptors in chronic constriction injury (CCI)-induced in vitro and lipopolysaccharide (LPS)-induced SH-SY5Y in vitro neuroinflammatory models. von Frey filament and Hargreaves plantar tests were used to assess allodynia and hyperalgesia in the chronic constriction injury-induced neuropathic pain mouse model. Involvement of specific adrenoceptors were investigated using antagonists prazosin ( $\alpha_{1}$-adrenoceptor antagonist), idazoxan ( $\alpha_{2}$-adrenoceptor antagonist), metoprolol ( $\beta_{1}$-adrenoceptor antagonist), ICl 118,551 ( $\beta_{2}$-adrenoceptor antagonist), and SR $59230 \mathrm{~A}$ ( $\beta_{3}$-adrenoceptor antagonist), co-administered with zerumbone $(10 \mathrm{mg} / \mathrm{kg})$. Involvement of excitatory receptors; TRPV and NMDA were conducted using antagonists capsazepine (TRPV1 antagonist) and memantine (NMDA antagonist). Western blot was conducted to investigate the effect of zerumbone on the expression of $\alpha_{2 A}$-adrenoceptor, TRPV1 and NMDA NR2B receptors in CCl-induced whole brain samples of mice as well as in LPSinduced SH-SY5Y neuroblastoma cells. Pre-treatment with $\alpha_{1}$-and $\alpha_{2}$-adrenoceptor antagonists significantly attenuated both anti-allodynic and anti-hyperalgesic effects of zerumbone. For $\beta$-adrenoceptors, only $\beta_{2}$-adrenoceptor antagonist significantly reversed 
the anti-allodynic and anti-hyperalgesic effects of zerumbone. $\beta_{1}$-adrenoceptor antagonist only reversed the anti-allodynic effect of zerumbone. The anti-allodynic and anti-hyperalgesic effects of zerumbone were both absent when TRPV1 and NMDA receptors were antagonized in both nociceptive assays. Zerumbone treatment markedly decreased the expression of $\alpha_{2 A^{-}}$ adrenoceptor, while an up-regulation was observed of NMDANR2B receptors. Expression of TRPV1 receptors however did not significantly change. The in vitro study, representing a peripheral model, demonstrated the reduction of both NMDA NR2B and TRPV1 receptors while significantly increasing $\alpha_{2 A}$-adrenoceptor expression in contrast to the brain samples. Our current findings suggest that the $\alpha_{1^{-}}, \alpha_{2^{-}}, \beta_{1}$ - and $\beta_{2}$-adrenoceptors, TRPV1 and NMDA NR2B are essential for the anti-allodynic and antihyperalgesic effects of zerumbone. Alternatively, we demonstrated the plasticity of these receptors through their response to zerumbone's administration.

Keywords: zerumbone, neuropathic pain, $\alpha_{2 A}$-adrenoceptor, TRPV1, NMDA NR2B, allodynia and hyperalgesia

\section{INTRODUCTION}

Zingiber zerumbet (Z. zerumbet) Smith is a wild ginger plant species that has long been used as traditional medicine in Southeast Asia. From rhizomes of $Z$. zerumbet, the main bioactive compound zerumbone has been isolated. Zerumbone has been shown to possess anti-inflammatory (Chien et al., 2008; Sulaiman et al., 2010a), antinociceptive (Sulaiman et al., 2010b), chemopreventive (Murakami et al., 1999), antimicrobial, and anti-oxidative properties (Habsah et al., 2000). Most importantly, we have reported the anti-allodynic and antihyperalgesic properties of zerumbone in a neuropathic pain mouse model (Zulazmi et al., 2015; Chia et al., 2016; Zulazmi et al., 2017).

The prevalence of neuropathic pain in the society is unfortunately increasing at a worrying rate. A pain condition due to lesions or diseases that affect the somatosensory nervous system give rise to neuropathic pain (Merskey, 1986). This debilitating chronic pain condition is common to those who suffer from diabetes, tumor nerve compression, viruses (HIV, varicella zoster virus), central nervous system disorders (multiple sclerosis, stroke), and surgical procedures (Baron and Tolle, 2008; Jensen et al., 2009).

The descending pain pathway plays an important role in modulating nociceptive signals, where bidirectional facilitatory or inhibitory control of nociception occurs. The periaqueductal gray (PAG) and rostroventromedial medulla (RVM) have been established as brain structures that provide the most influence on the descending pain pathway (Basbaum and Fields, 1978; Gebhart, 2004; Tracey and Mantyh, 2007). The monoaminergic system mainly utilizes serotonin and noradrenaline neurotransmitters in modulating nociception. These monoamines will act upon their respective subtypes to activate either the descending inhibitory or facilitatory pain pathway (Bannister and Dickenson, 2016).

As we have already shown the involvement of serotonergic system in the anti-neuropathic properties of zerumbone (Chia et al., 2016), this study will further explore the noradrenergic receptors of the monoaminergic system. Projections of noradrenergic neurons to the spinal cord arise from the pontine nuclei, mainly the A5, A6 (locus coeruleus), and A7 (Kölliker-Füse). The PAG and RVM brain structures communicate with these regions to modulate nociceptive transmission (Holden and Proudfit, 1998; Bajic and Proudfit, 1999; Pertovaara, 2006; Bruinstroop et al., 2012). The feedback mechanism of the noradrenergic system in terms of nociceptive modulation occurs following stimulation of sympathetic postganglionic axons, inducing release of noradrenaline neurotransmitters. The neurotransmitter released will then act upon adrenergic receptors to activate downstream effector molecules to inhibit nociceptive transmission (Pertovaara, 2013).

Apart from the descending modulatory controls, other receptors also play a role in inhibiting nociceptive signals. Excitatory receptor; transient receptor potential vanilloid 1 (TRPV1) and $N$-methyl-D-aspartate (NMDA) receptors are known to be involved in transmission of nociception. This is due to their localization on nociceptive neurons and pathophysiological changes in relation to their relative neurotransmitters, altering the activation threshold of action potential (Baron, 2006; Yogeeswari et al., 2009). Targeting of these excitatory receptors through agents that antagonize or agonize have shown promising results. Capsaicin cream, for example, is a TRPV agonist and is clinically used for chronic pain (Anand and Bley, 2011).

Multiple pathways and receptors in our body's physiological system intertwine to modulate pain signaling pathways. The underlying mechanism of zerumbone's anti-allodynic and antihyperalgesic effects should be investigated to further potentiate its effectiveness as an analgesic. Therefore, the main objectives of this study were to (1) determine the involvement of the noradrenergic, TRPV and NMDA receptors in the antiallodynic and antihyperalgesic effects of zerumbone and (2) observe the change in $\alpha_{2 \mathrm{~A}}$-adrenoceptor, TRPV1 and NMDA NR2B receptors expression in the brain regions following zerumbone treatment in neuropathic pain conditions as well as complementing our findings with the in vitro LPS-induced 
SH-SY5Y neuroblastoma neuroinflammation model for peripheral involvement.

\section{MATERIALS AND METHODS}

\section{Experimental Animals}

Male ICR mice (6-8 weeks, $25-35 \mathrm{~g}$ ) were used in this study. All mice were housed under a $12 \mathrm{~h} \mathrm{light/dark}$ cycle at $24 \pm 1^{\circ} \mathrm{C}$ with unlimited access to food and water. Handling of animals and experiments were conducted according to the Ethical Guidelines for Investigation of Experimental Pain in Conscious Animals (Zimmermann, 1983) by the International Association for the Study of Pain (IASP). This study has been approved by the Institutional Animal Care and Use Committee (IACUC) UPM (Ref: UPM/IACUC/AUP- R060/2013).

\section{Chronic Constriction Injury}

The surgery to induce neuropathic pain was adapted from (Bennett and Xie, 1988) with some modifications (Gopalsamy et al., 2019). Briefly, mice were anaesthetized with tribromoethanol $(250 \mathrm{mg} / \mathrm{kg}$, i.p.). After shaving the fur on the left thigh region, the sciatic nerve was exposed after an incision was made through the biceps femoris. One loose ligature was placed using a 4-0 braided silk suture until a slight twitch of the left limb was observed. Same surgical procedures were conducted in mice from the sham group, except without ligation of the sciatic nerve. Mice were allowed to recover and behavioral tests were conducted on the $14^{\text {th }}$ day after CCI.

\section{Zerumbone}

Compound extraction and isolation were conducted as previously reported (Chia et al., 2016). Zerumbone was dissolved in dimethylsulfoxide (DMSO), Tween 20 and normal saline $(0.99 \% \mathrm{NaCl})$ in a ratio of $5: 5: 90(\mathrm{v} / \mathrm{v})$. The final concentration of DMSO did not exceed $5 \%$ of the total volume and caused no detectable effect on its own. Zerumbone was administered at $10 \mathrm{mg} / \mathrm{kg}$ through the intraperitoneal route based on our previous studies (Zulazmi et al., 2015; Chia et al., 2016; Zulazmi et al., 2017). The dosage of zerumbone (10 mg/kg) was chosen based on previous studies published by our colleagues Zulazmi et al. (2015), where they found zerumbone at $10 \mathrm{mg} / \mathrm{kg}$ was sufficient to provide anti-allodynic and antihyperalgesic properties in the CCI-induced neuropathic pain mice model. Figures $\mathbf{S} 1$ and $\mathbf{S} 2$ are included as supplementary to provide clarity. In addition, the $\mathrm{ED}_{50}$ of zerumbone in a similar neuropathic pain mice model was reported to be $10 \mathrm{mg} / \mathrm{kg}$ (Gopalsamy et al., 2017). For the in vitro assays, zerumbone was dissolved in phosphate buffered saline (PBS) at $0.25 \mathrm{mg} / \mathrm{ml}$ as stock solution.

\section{Behavioral Tests} von Frey Filament Test

Mechanical allodynia was evaluated using the Electronic von Frey Aesthesiometer (IITC, Woodland Hills, CA, USA), adapted from methods by Chaplan et al. (1994). Mice were individually placed in the set-up of clear Plexiglass boxes placed on a wire-mesh platform. The automatic thin steel von Frey filament was positioned under the midplantar surface of the hindpaw. A gradual increase in force was applied until withdrawal of the paw was observed, measuring the maximum force of a mechanical stimulus to elicit a response. Withdrawal thresholds of force greater than $4.5 \mathrm{~g}$ was the cut-off point to avoid paw damage.

\section{Hargreaves Plantar Test}

Thermal hyperalgesia was evaluated using the thermal plantar apparatus (Ugo-basile, 37370, Verase, Italy), adapted from methods by Hargreaves et al. (1988). Mice were individually placed in the set-up clear Plexiglass boxes placed on a glass platform. The radiant heat source was positioned under the midplantar surface of the hindpaw, measuring the withdrawal latency for the mice to lift its paw. Cut-off point to avoid tissue damage was set at $20 \mathrm{~s}$.

\section{In Vivo Analysis of the Mechanisms of Action of Zerumbone}

Involvement of Noradrenergic System

To firstly investigate the involvement of noradrenergic receptors, non-specific noradrenaline receptor antagonists were used; phentolamine (non-selective $\alpha$-adrenoceptor antagonist, $5 \mathrm{mg} / \mathrm{kg}$ ) and propranolol (non-selective $\beta$-adrenoceptor antagonist, $5 \mathrm{mg} / \mathrm{kg}$ ).

Following confirmation of the involvement of $\alpha$-adrenoceptors, further investigation into the specific noradrenergic receptor subtypes was conducted using selective $\alpha$-adrenoceptor antagonists; prazosin $\left(\alpha_{1}\right.$-adrenoceptor antagonist, $\left.10 \mathrm{mg} / \mathrm{kg}\right)$, idazoxan $\left(\alpha_{2}\right.$-adrenoceptor antagonist, $\left.2 \mathrm{mg} / \mathrm{kg}\right)$. Specific $\beta$ adrenoceptor antagonists metoprolol $\left(\beta_{1}\right.$-adrenoceptor antagonist, $1 \mathrm{mg} / \mathrm{kg})$, ICI 118,551 ( $\beta_{2}$-adrenoceptor antagonist, $\left.2 \mathrm{mg} / \mathrm{kg}\right)$, and SR $59230 \mathrm{~A}\left(\beta_{3}\right.$-adrenoceptor antagonist, $\left.2.5 \mathrm{mg} / \mathrm{kg}\right)$ were used following confirmation of the involvement of $\beta$-adrenoceptors.

Vehicle or zerumbone $(10 \mathrm{mg} / \mathrm{kg})$ were administered $30 \mathrm{~min}$ following antagonists' administration. Following $30 \mathrm{~min}$ after last respective treatments, behavioral tests were conducted.

Phentolamine, propranolol, metoprolol, and SR 59230 A were dissolved in $0.9 \% \mathrm{NaCl}$, ICI 118,551 was dissolved in 5\% DMSO, $95 \%$ normal saline $(0.9 \% \mathrm{NaCl})$ and idazoxan was dissolved in $10 \%$ DMSO and $90 \%$ normal saline $(0.9 \% \mathrm{NaCl})$. Phentolamine, propranolol, ICI 118, 551, and SR 59230 A were administered in a volume of $5 \mathrm{ml} / \mathrm{kg}$ while idazoxan and metoprolol were administered in a volume of $10 \mathrm{ml} / \mathrm{kg}$. All injections were intraperitoneal, $30 \mathrm{~min}$ prior to zerumbone administration. Dosages were chosen based on previous literature (Yalcin et al., 2009a; Yalcin et al., 2009b; Zhao et al., 2012).

\section{Involvement of Excitatory Receptors}

To assess the possible involvement of excitatory receptorsTRPV1 and NMDA, in the anti-allodynic and antihyperalgesic effects of zerumbone, mice were pre-administered with antagonists prior to zerumbone. Antagonists used were capsazepine (TRPV1 receptor antagonist, $10 \mathrm{mg} / \mathrm{kg}$ ) and memantine (NMDA receptor antagonist, $10 \mathrm{mg} / \mathrm{kg}$ ).

Vehicle or zerumbone $(10 \mathrm{mg} / \mathrm{kg})$ were administered $30 \mathrm{~min}$ following antagonists' administration. Following $30 \mathrm{~min}$ after last respective treatments, behavioral tests were conducted. 
Capsazepine and memantine were dissolved in $0.9 \% \mathrm{NaCl}$ and were administered intraperitoneally, in a volume of $10 \mathrm{ml} /$ kg. Dosages were chosen based on previous studies (Eisenberg et al., 1995; Costa et al., 2008).

\section{Western Blot Analysis}

Protein analyses were conducted to evaluate the changes in expression level of $\alpha_{2 \mathrm{~A}}$-adrenergic, TRPV1 and NMDA NR2B receptors following neuropathic pain induction and zerumbone treatment. Selection of receptor subtypes were based on behavioral test results and the significant roles played by the receptors in neuropathic pain conditions.

Following behavioral tests, whole brain tissue samples were collected from the experimental animals. Tissue samples were homogenized in cold RIPA lysis buffer with protease inhibitors and the supernatants collected after centrifugation $(6,000 \mathrm{~g} 30$ min, $4^{\circ} \mathrm{C}$ ) stored at $-20^{\circ} \mathrm{C}$ until further usage. Sample supernatants $(80 \mu \mathrm{g})$ were resolved on $8-12 \%$ sodium dextran sulfate-polyacrylamide gels, followed by protein transfer to a polyvinylidene fluoride (PVDF) membrane (Pall Life Sciences, Port Washington, NY, USA). The blots were then blocked with $5 \%$ Bovine Serum Albumin (BSA) in TBST (Tris Buffer Saline with $0.1 \%$ Tween 20 ) for $1 \mathrm{~h}$. After blocking, blots were incubated overnight with anti- $\alpha_{2 A}$ adrenergic receptor (1:500, PA1-048, Thermo Fisher Scientific, USA), anti-VR1 (1:1,000, ab31895, Abcam, USA), or anti-NR2B (1:1,000, ab65783, Abcam, USA) primary antibodies. Blots were then incubated for $1 \mathrm{~h}$ with horseradish peroxidase (HRP)-conjugated secondary antibodies (1:5,000, ab97051, Abcam, USA) following sufficient washing with TBST. Blots were washed four times, 20 min each time, with TBST prior to detection using enhanced chemiluminescent (ECL) detection system (Perkin Elmer, USA). Protein bands were analyzed and quantified using ImageJ processing software (National Institutes of Health). Blots were stripped and reprobed with HRP-conjugated anti- $\beta$-actin (1:5,000, ab20272, Abcam, USA) for one hour. Bands corresponding to $\beta$-actin were normalized to protein bands of samples.

\section{In Vitro Analysis of the Mechanisms of Action of Zerumbone Cell Culture}

Dulbecco's Modified Essential Medium/Ham's Nutrient Mixture (DMEM:F12), Penicillin-Streptomycin solution and $2.5 \mathrm{~g} / \mathrm{l}$ Trypsin/1mmol/l-EDTA Solution were purchased from Nacalai Tesque (Tokyo, Japan). Fetal bovine serum (FBS) and nonessential amino acids (NEAA) was purchased from Gibco-BRL (Grand Island, NY). Lipopolysaccharide (LPS) from Escherichia coli O55:B5 was purchased from Merck (Darmstadt, Germany).

SH-SY5Y neuroblastoma cell line were purchased from ATCC $\left(\right.$ ATCC $^{\circledR}$ CRL-2266 ${ }^{\mathrm{TM}}$ ). The cells were initially grown in Dulbecco's Modified Essential Medium (DMEM:F12) which contains $4.5 \mathrm{~g} / \mathrm{l}$ glucose with $2 \mathrm{mM}$ of L-glutamine and sodium pyruvate, supplemented with $15 \%$ FBS, $1 \%$ of Penicillin-Streptomycin mixed solution and $1 \% \mathrm{NEAA}$ at $37^{\circ} \mathrm{C}$ with $5 \%$ carbon dioxide $\left(\mathrm{CO}_{2}\right)$. Then, the cells were induced with $10 \mu \mathrm{M}$ of all-trans retinoic acid for 5 days in a differentiation media (DMEM:F12, supplemented with $2.5 \%$ fetal bovine serum (FBS) and 1\% of Penicillin-Streptomycin mixed solution) (Forster et al., 2016; Izham et al., 2018).

\section{LPS-Induction and Treatment Groups}

Following differentiation, the cells were induced with $1 \mu \mathrm{g} / \mathrm{ml}$ of LPS for $12 \mathrm{~h}$ at $37^{\circ} \mathrm{C}$ with $5 \% \mathrm{CO}_{2}$ to induce neuronal sensitization (Das et al., 2012). After LPS induction, $8 \mu \mathrm{g} / \mathrm{ml}$ zerumbone, $16 \mu \mathrm{g} / \mathrm{ml}$ amitriptyline as a positive control and vehicle (PBS) were added to the LPS-induced cell culture and incubated for $24 \mathrm{~h}$ at $37^{\circ} \mathrm{C}$ with $5 \% \mathrm{CO}_{2}$. The whole culture media was not removed and the amount of treatment required were calculated respectively.

\section{Western Blot Analysis of $\alpha_{2 A}$-Adrenergic, TRPV1 and NMDA NR2B Receptors}

In order to extract protein from the cell culture, ice-cold PBS was added to rinse the cell culture following $24 \mathrm{~h}$ of treatment. Then, $200 \mu \mathrm{l}$ of RIPA lysis buffer (with protease inhibitor) was added and the cells were scrapped using the cell scrapper. The sample was then centrifuged at $10,000 \mathrm{rpm}$ for $10 \mathrm{~min}$ at $4^{\circ} \mathrm{C}$. The supernatant was collected for protein quantification and sodium dodecyl sulfate polyacrylamide gel electrophoresis (SDS-PAGE). The protein concentration was determined by using BCA protein assay (Pierce $^{\mathrm{TM}}$ BCA Protein Assay Kit). $10 \mu \mathrm{g}$ of protein sample was prepared by mixing the protein sample and the sample loading buffer (1:1). The protein was separated through SDS-PAGE at 120V for $2 \mathrm{~h}$. Then, the protein was transferred to Polyvinylidene fluoride or polyvinylidene difluoride (PVDF) membrane at $0.35 \mathrm{~A}$ for $2 \mathrm{~h}$ in ice. After transfer, the blot was blocked with $5 \%$ skimmed milk in TBST [mixture of tris-buffered saline (TBS) and Tween-20] for $1 \mathrm{~h}$. Then, the blot was incubated overnight at $4^{\circ} \mathrm{C}$ with polyclonal antibody against $\beta$-actin (1: 5,000, \#12620, Cell Signalling Technology, Danvers, MA, USA), with monoclonal antibody against GluN2B (NMDA receptor) (1:1,000, \#4212, Cell Signalling Technology, Danvers, MA, USA), with polyclonal antibody against Alpha- ${ }_{2 \mathrm{~A}}\left(\alpha_{2 \mathrm{~A}}\right)$ adrenoceptor (1:1,000, ab85570, Abcam, Cambridge, MA, USA) and with polyclonal antibody against TRPV1 (1:500, bs-1931R, Bioss, MA, USA). After primary antibody incubation, the blots were incubated in secondary antibody (anti-rabbit IgG HRP-linked, 1:2,000, \#7074S, Cell Signalling Technology, Danvers, MA, USA) for $1 \mathrm{~h}$ at room temperature with continuous agitation. Following incubation, the blots were developed by using ECL solution (Advansta, USA) and the chemiluminescence were detected by ChemiDoc ${ }^{\mathrm{TM}}$ imaging system. The band intensity quantification was carried out through the basis of molecular weight by using NIH ImageJ software.

\section{Data Analysis}

All results are expressed as mean \pm standard error of mean (S.E.M.). Parametric values were analyzed by one-way ANOVA followed by Tukey's post hoc test using Graphpad Prism v6.0 software (Graphpad San Diego, CA). P values of less than 0.05 were considered significant.

Full images of blots with ladders are provided as supplementary materials, Figures S3-S5. Blots shown in the manuscript are images from full blots as provided in the supplementary materials, Figures S6-S9. 


\section{RESULTS}

\section{Involvement of Noradrenergic System in the Anti-Allodynic and Antihyperalgesic Effects of Zerumbone}

Before investigating specific adrenoceptors involved in the antineuropathic effects of zerumbone, $\alpha$-adrenoceptors and $\beta$ adrenoceptors were non-selectively blocked to determine the involvement of $\alpha$ and $\beta$ noradrenergic receptors. Phentolamine ( $5 \mathrm{mg} / \mathrm{kg}, \mathrm{i}, \mathrm{p}$.) and propranolol $(5 \mathrm{mg} / \mathrm{kg}$, i.p.), non-specific $\alpha$ and $\beta$-adrenoceptor antagonists respectively, were preadministered prior to zerumbone $(10 \mathrm{mg} / \mathrm{kg}$, i.p.). Administration of antagonists alone did not significantly affect allodynia and hyperalgesia induced by CCI (Figure 1, Figure 2). As shown in Figure 1, pre-treatment with phentolamine significantly $(p<0.0001)$ abolished the anti-allodynic effect of zerumbone. Similarly, the anti-allodynic effect of zerumbone was also abolished in the presence of propranolol $(p<0.0001)$. In Figure 2, similarly pre-treatment with both phentolamine and propranolol attenuated the antihyperalgesic effect of zerumbone.

\section{Effects of $\alpha$-Adrenoceptors Antagonists on Zerumbone-Induced Antineuropathy}

As the non-specific $\alpha$-adrenoceptor antagonist attenuated the antineuropathic effects of zerumbone, further investigation into specific adrenoceptor subtypes were conducted. Specific $\alpha$-adrenoceptor antagonists to $\alpha_{1}$ and $\alpha_{2}$, prazosin and idazoxan respectively, significantly $(p<0.0001)$ prevented the anti-allodynic effect of zerumbone in the von Frey Filament Test as shown in Figure 3. The antihyperalgesic effect of zerumbone was similarly absent $(p<$ $0.0001)$ in the Hargreaves Plantar Test when $\alpha_{1^{-}}$and $\alpha_{2^{-}}$ adrenoceptor antagonists were co-administered with zerumbone as shown in Figure 4. Administration of antagonists alone did not significantly affect allodynia and hyperalgesia induced by CCI (Figures 3, 4).

\section{In Vivo Analysis of the Mechanisms of Action of Zerumbone Effects of $\beta$-Adrenoceptors Antagonists on Zerumbone-Induced Anti-Neuropathy}

As pre-administration of the non-selective $\beta$-adrenoceptor attenuated the anti-neuropathic effects of zerumbone, specific $\beta$-adrenoceptors were then investigated. In Figure 5, the antiallodynic effect of zerumbone was investigated in the presence of $\beta_{1^{-}}, \beta_{2^{-}}$, and $\beta_{3^{-}}$-adrenoceptor antagonists. Metoprolol and ICI 118,551 , antagonists to $\beta_{1^{-}}$and $\beta_{2}$-adrenoceptors respectively, significantly $(p<0.0001)$ attenuated the anti-allodynic effect of zerumbone. However, SR $59230 \mathrm{~A}$, antagonist to $\beta_{3}$-adrenoceptor, did not reverse the anti-allodynic effect of zerumbone. In Figure 6, the antihyperalgesic effect of zerumbone was attenuated $(p<$ 0.0001 ) only in the presence of ICI 118,551 , a $\beta_{2}$-adrenoceptor antagonist. When metoprolol and SR $59230 \mathrm{~A}$ antagonists were preadministered prior to zerumbone, the withdrawal latency was not significantly different when compared to zerumbone. Administration of antagonists alone did not significantly affect allodynia and hyperalgesia induced by CCI (Figures 5 and $\mathbf{6}$ ).

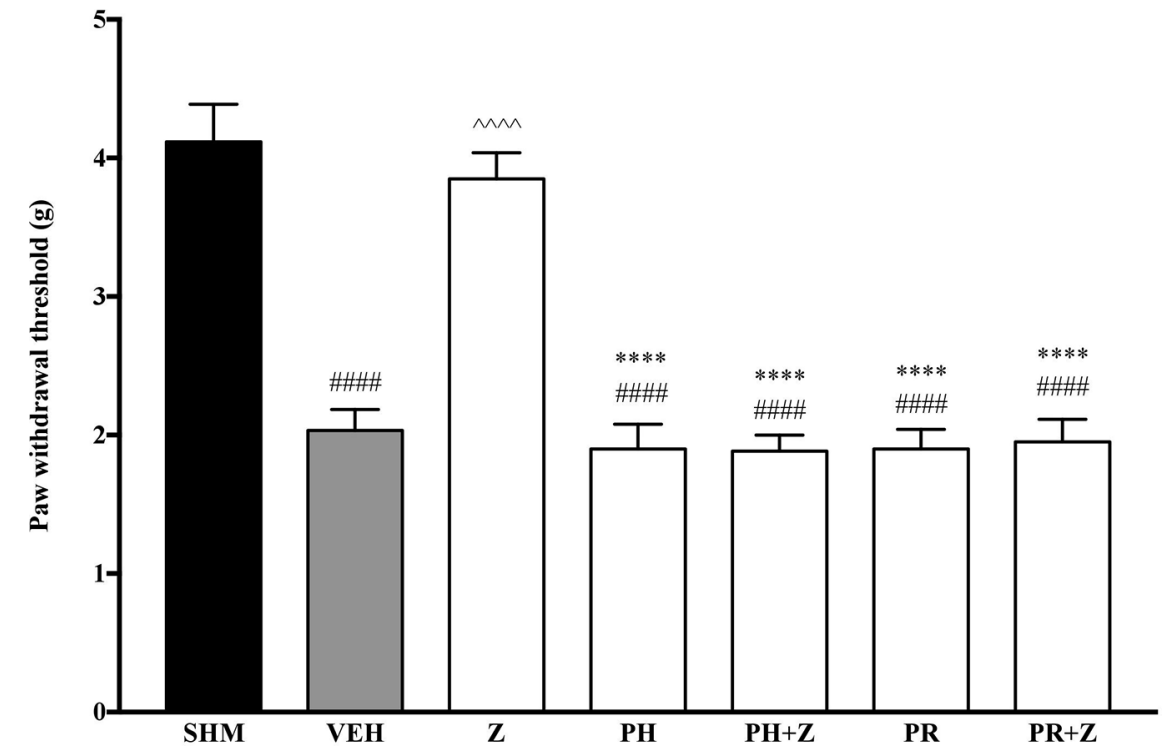

FIGURE 1 | Effect of phentolamine (non-selective $\alpha$-adrenoceptor antagonist) and propranolol (non-selective $\beta$-adrenoceptor antagonist) pre-treatment on zerumbone against mechanical allodynia in CCl-induced neuropathic pain mice. Data are presented as mean $\pm \mathrm{SEM}(\mathrm{n}=6)$. ${ }^{\# \# \# ~} p<0.0001$ as compared to sham, ${ }^{\wedge \wedge} p<0.0001$ as compared to vehicle and ${ }^{\star \star \star \star} p<0.0001$ as compared to zerumbone-treated group. SHM (Sham); VEH (Vehicle, $10 \mathrm{~mL} / \mathrm{kg}$ i.p.); Z (Zerumbone, 10 mg/kg i.p.); PH (Phentolamine, 5 mg/kg i.p.); PR (Propranolol, 5 mg/kg i.p.). 


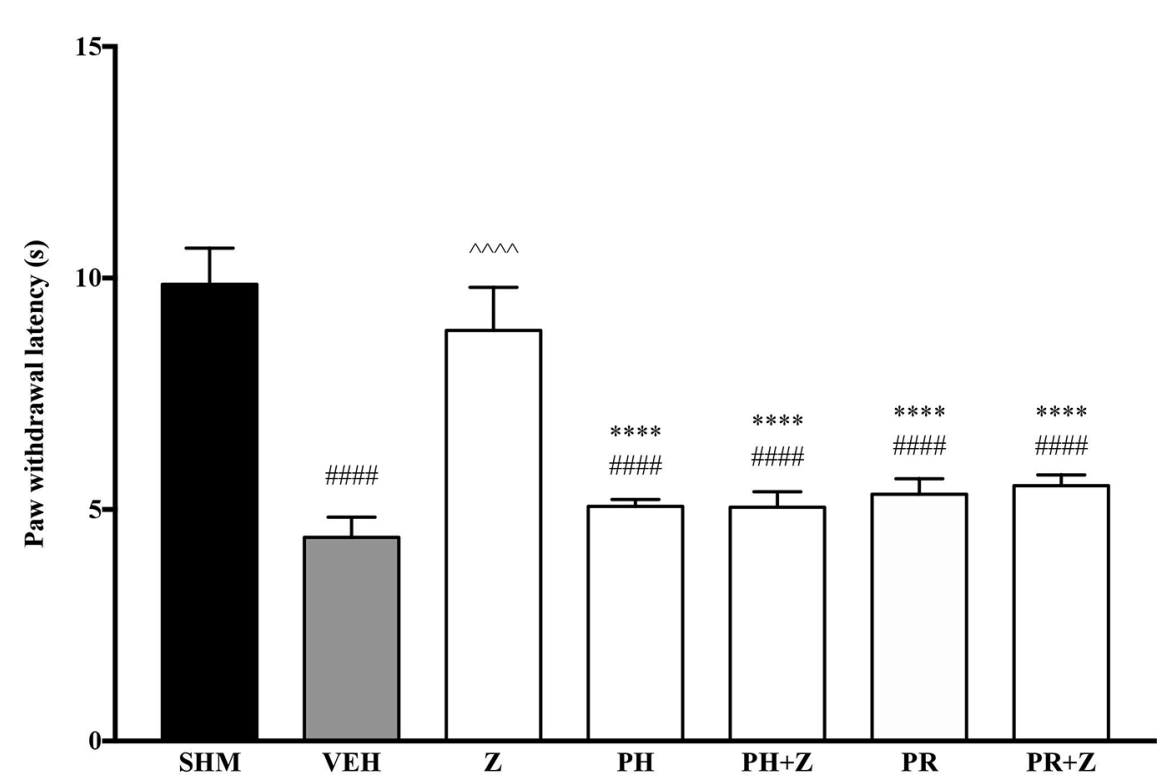

FIGURE 2 | Effect of phentolamine (non-selective $\alpha$-adrenoceptor antagonist) and propranolol (non-selective $\beta$-adrenoceptor antagonist) pre-treatment on zerumbone against thermal hyperalgesia in CCl-induced neuropathic pain mice. Data are presented as mean $\pm \mathrm{SEM}(\mathrm{n}=6){ }^{\# \# \# \#} p<0.0001$ as compared to sham, $\wedge \wedge \wedge \wedge p<0.0001$ as compared to vehicle and ${ }^{\star \star \star \star \star} p<0.0001$ as compared to zerumbone-treated group. SHM (Sham); VEH (Vehicle, $10 \mathrm{ml} / \mathrm{kg}$ i.p.); Z (Zerumbone, 10 mg/kg i.p.); PH (Phentolamine, 5 mg/kg i.p.); PR (Propranolol, 5 mg/kg i.p.).

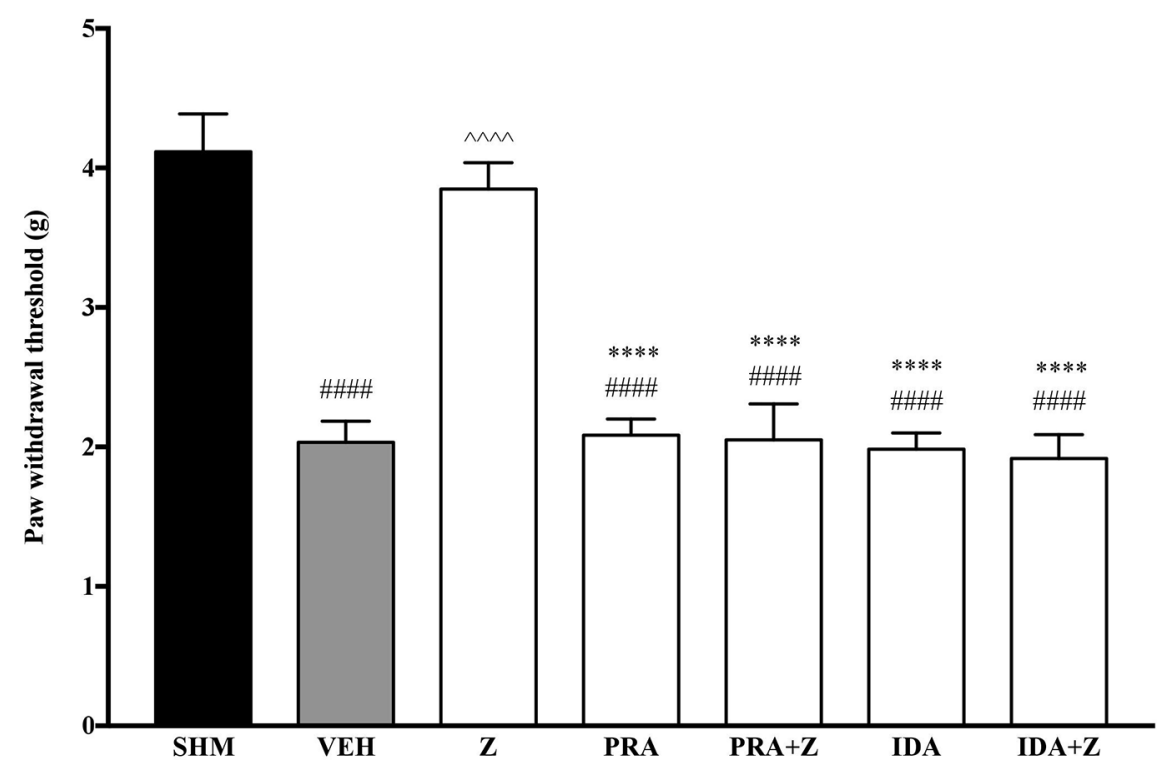

FIGURE 3 | Effect of prazosin ( $\alpha_{1}$-adrenoceptor antagonist) and idazoxan ( $\alpha_{2}$-adrenoceptor antagonist) pre-treatment on zerumbone against mechanical allodynia in

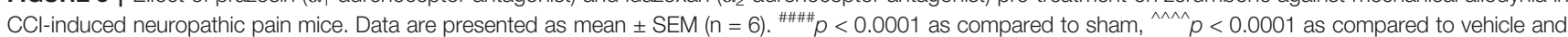
${ }^{\star \star \star \star} p<0.0001$ as compared to zerumbone-treated group. SHM (Sham); VEH (Vehicle, 10 mL/kg i.p.); Z (Zerumbone, 10 mg/kg i.p.); PRA (Prazosin, 10 mg/kg i.p.); IDA (Idazoxan, $2 \mathrm{mg} / \mathrm{kg}$ i.p.). 


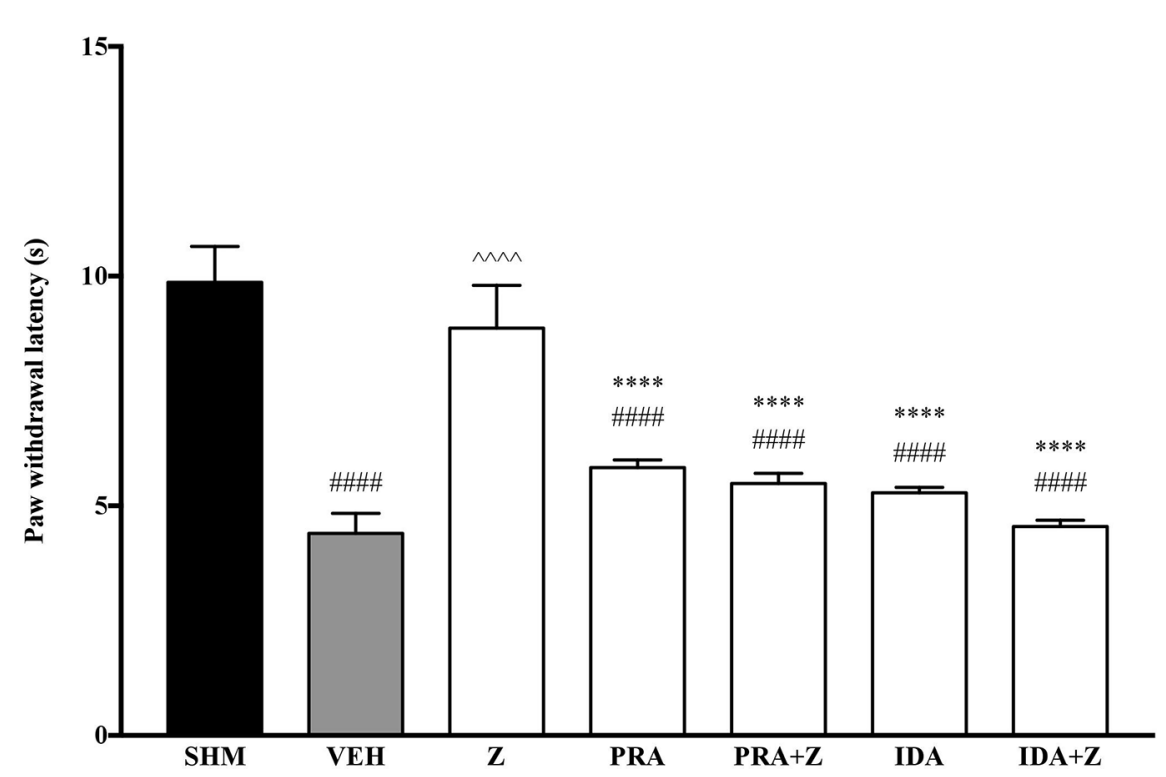

FIGURE 4 | Effect of prazosin ( $\alpha_{1}$-adrenoceptor antagonist) and idazoxan ( $\alpha_{2}$-adrenoceptor antagonist) pre-treatment on zerumbone against thermal hyperalgesia in

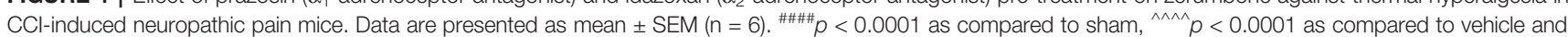
${ }^{\star \star \star \star} p<0.0001$ as compared to zerumbone-treated group. SHM (Sham); VEH (Vehicle, $10 \mathrm{~mL} / \mathrm{kg}$ i.p.); Z (Zerumbone, $10 \mathrm{mg} / \mathrm{kg}$ i.p.); PRA (Prazosin, $10 \mathrm{mg} / \mathrm{kg}$ i.p.); IDA (Idazoxan, 2 mg/kg i.p.).

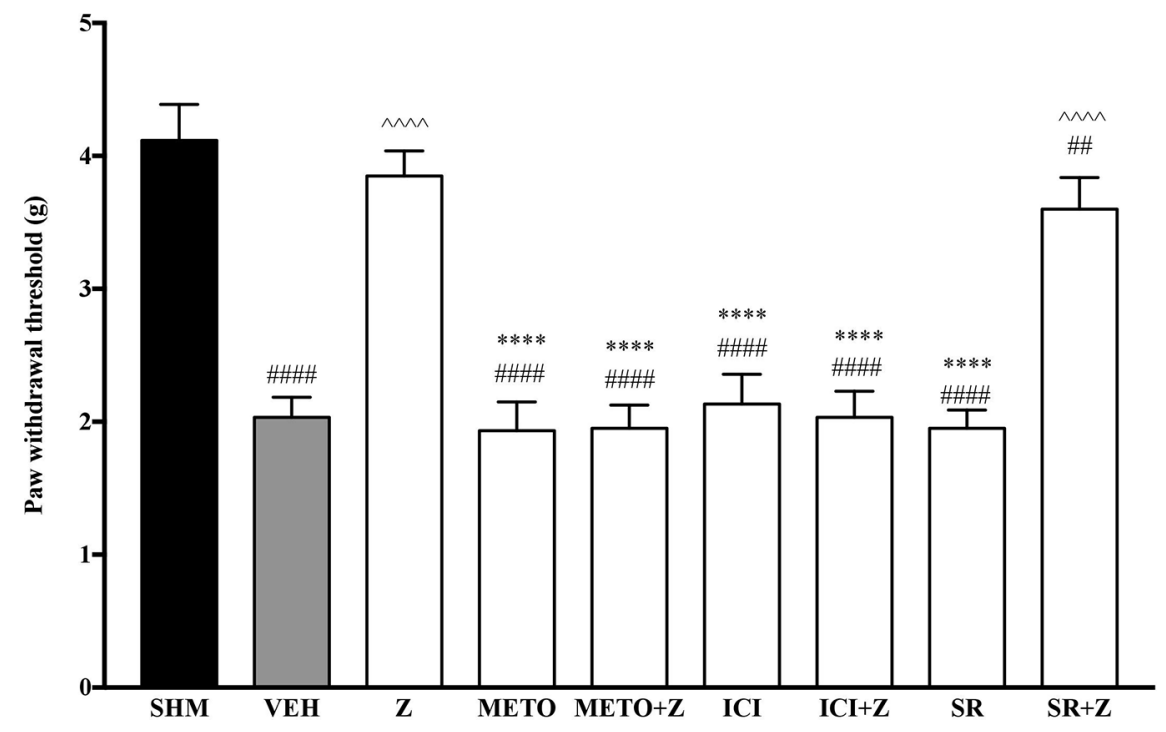

FIGURE 5 | Effect of metoprolol ( $\beta_{1}$-adrenoceptor antagonist), ICl 118, 551 ( $\beta_{2}$-adrenoceptor antagonist) and SR 59230 A ( $\beta_{3}$-adrenoceptor antagonist) pretreatment on zerumbone against mechanical allodynia in CCl-induced neuropathic pain mice. Data are presented as mean $\pm \mathrm{SEM}(\mathrm{n}=6)$. ${ }^{\# \#} p<0.01$, \#\#\#\# $p<0.0001$ as compared to sham, ${ }^{\wedge \wedge \wedge} p<0.0001$ as compared to vehicle and ${ }^{\star \star \star *} p<0.0001$ as compared to zerumbone-treated group. SHM (Sham); VEH (Vehicle, $10 \mathrm{~mL} / \mathrm{kg}$ i.p.); Z (Zerumbone, 10 mg/kg i.p.); METO (Metoprolol, 1 mg/kg i.p.); ICl (ICl 118,551, 2 mg/kg i.p.); SR (SR 59230 A, 2.5 mg/kg i.p.). 


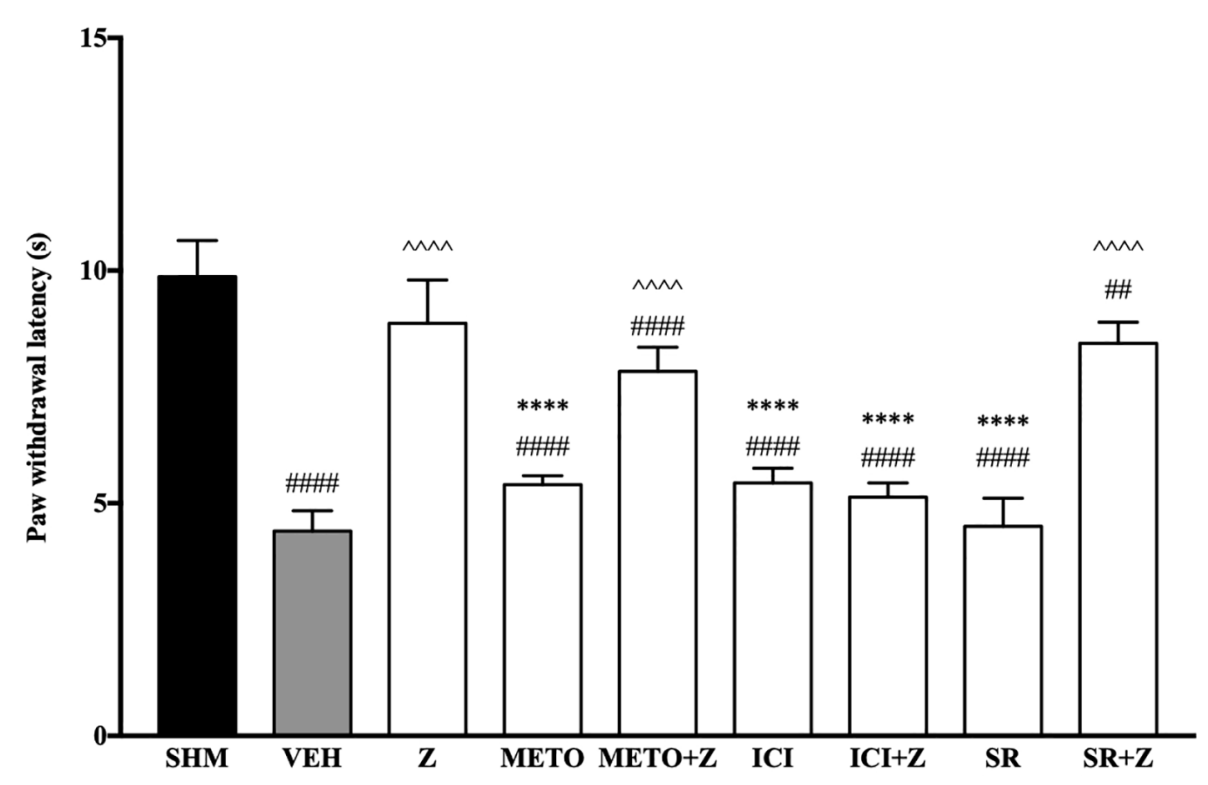

FIGURE 6 | Effect of metoprolol ( $\beta_{1}$-adrenoceptor antagonist), ICl 118, 551 ( $\beta_{2}$-adrenoceptor antagonist) and SR 59230 A ( $\beta_{3}$-adrenoceptor antagonist) pretreatment on zerumbone against thermal hyperalgesia in CCl-induced neuropathic pain mice. Data are presented as mean $\pm \mathrm{SEM}(\mathrm{n}=6)$. ${ }^{\# \#} p<0.01$, \#\#\#\# $p<0.0001$ as compared to sham, ${ }^{\wedge \wedge \wedge} p<0.0001$ as compared to vehicle and ${ }^{\star \star \star \star} p<0.0001$ as compared to zerumbone-treated group. SHM (Sham); VEH (Vehicle, $10 \mathrm{~mL} / \mathrm{kg}$ i.p.); Z (Zerumbone, 10 mg/kg i.p.); METO (Metoprolol, 1 mg/kg i.p.); ICl (ICl 118,551, 2 mg/kg i.p.); SR (SR 59230 A, 2.5 mg/kg i.p.).

\section{Effect of Zerumbone on the Expression of $\alpha_{2 A^{-}}$ Adrenergic Receptor}

Changes in the expression of $\alpha_{2 \mathrm{~A}}$-adrenoceptor following CCI and zerumbone treatment were assessed using Western blot. Samples from mice brain on Day 14 revealed bands corresponding to $\alpha_{2 \mathrm{~A}}-\mathrm{AR}$ at $\sim 60 \mathrm{kDa}$. As shown in Figure 7, CCI causes a significant increase in expression of $\alpha_{2 \mathrm{~A}}$-AR as shown between vehicle and naïve groups $(p<0.001)$. In contrast, expression of $\alpha_{2 \mathrm{~A}}$-AR significantly $(p<0.05)$ decreased following zerumbone $(10 \mathrm{mg} / \mathrm{kg})$ treatment in comparison to vehicle group.

\section{Involvement of TRPV and NMDA Receptors in the Anti-Allodynic and Antihyperalgesic Effects of Zerumbone}

In Figure 8, the anti-allodynic effect of zerumbone was investigated in the presence of TRPV and NMDA receptor antagonists. Pre-treatment with capsazepine and memantine, antagonists to TRPV1 and NMDA respectively, significantly $(p<0.0001)$ attenuated the anti-allodynic effect of zerumbone. Similarly, the antihyperalgesic effect of zerumbone was also absent when antagonists capsazepine and memantine were pre-administered as shown in Figure 9. Administration of antagonists on its own did not affect paw withdrawal responses in both behavioral tests (Figures $\mathbf{8}$ and $\mathbf{9}$ ).

\section{Effect of Zerumbone on the Expression of TRPV1 Receptor}

Analysis on the expression of TRPV1 receptors were analyzed using brain samples of naïve, sham, vehicle, and zerumbone- treated mice. As shown in Figure 10, the bands observed corresponded to the expected molecular weight $\sim 94 \mathrm{kDa}$. The induction of neuropathic pain caused a significant $(p<0.05)$ upregulation of TRPV1 receptors, when comparing vehicle against sham group. No significant changes were observed between vehicle and zerumbone-treated groups. However, expression of TRPV1 receptors in zerumbone-treated groups is significantly $(p<0.01)$ higher against naïve and sham groups.

\section{Effect of Zerumbone on the Expression of NMDA NR2B Receptor}

The changes on NMDA NR2B receptor expression were analyzed following CCI and zerumbone treatment. As shown in Figure 11, the bands observed corresponded to the expected molecular weight $\sim 160 \mathrm{kDa}$. In vehicle group, no significant changes were observed of the NR2B receptor expression in comparison to naïve and sham groups. However, a significant $(p<0.05, p<0.01)$ up-regulation was observed in zerumbonetreated groups, compared against sham and vehicle groups.

\section{In Vitro Analysis of the Mechanisms of Action of Zerumbone Western Blot Analysis of $\alpha_{2 A}$-Adrenergic, TRPV1 and NMDA NR2B Receptors}

Changes in the expression of $\alpha_{2 \mathrm{~A}}$-adrenergic, TRPV1, and NMDA NR2B receptors in the LPS-induced SH-SY5Y neuroblastoma cells were analyzed $24 \mathrm{~h}$ after the administration of $8 \mu \mathrm{g} / \mathrm{ml}$ zerumbone, $16 \mu \mathrm{g} / \mathrm{ml}$ amitriptyline, and vehicle. As shown in Figure 12, zerumbone administration significantly 


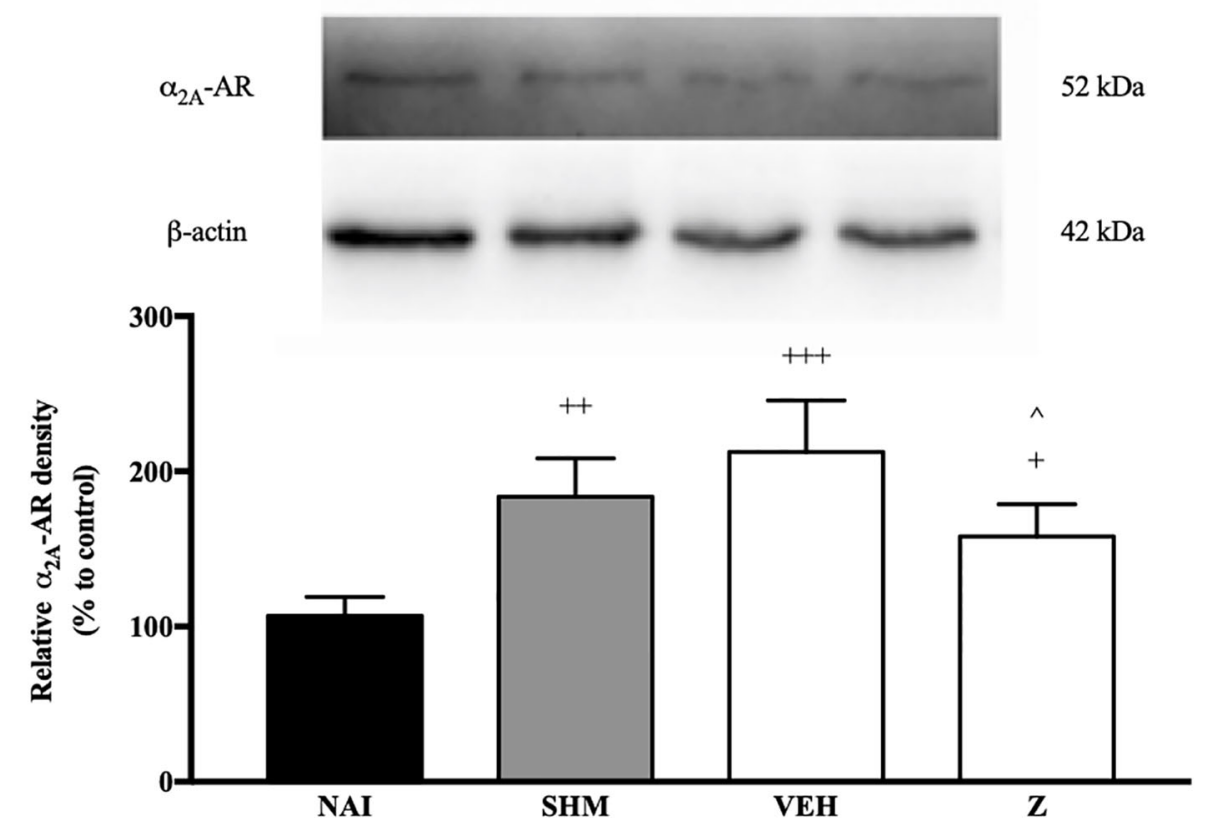

FIGURE 7 | Representative western blots of $\alpha_{2 A}$-adrenergic receptor from brain samples of naïve, sham, vehicle and zerumbone-treated groups. Data presented as mean \pm SEM $(n=4)$, which were normalized to $\beta$-actin. ${ }^{+} p<0.05,{ }^{++} p<0.01,{ }^{+++} p<0.001$ as compared to naïve and ${ }^{\wedge} p<0.05$ as compared to vehicle group. NAI (Naïve); SHM (Sham); VEH (Vehicle, $10 \mathrm{~mL} / \mathrm{kg}$ ); Z (Zerumbone, $10 \mathrm{mg} / \mathrm{kg}$ ).

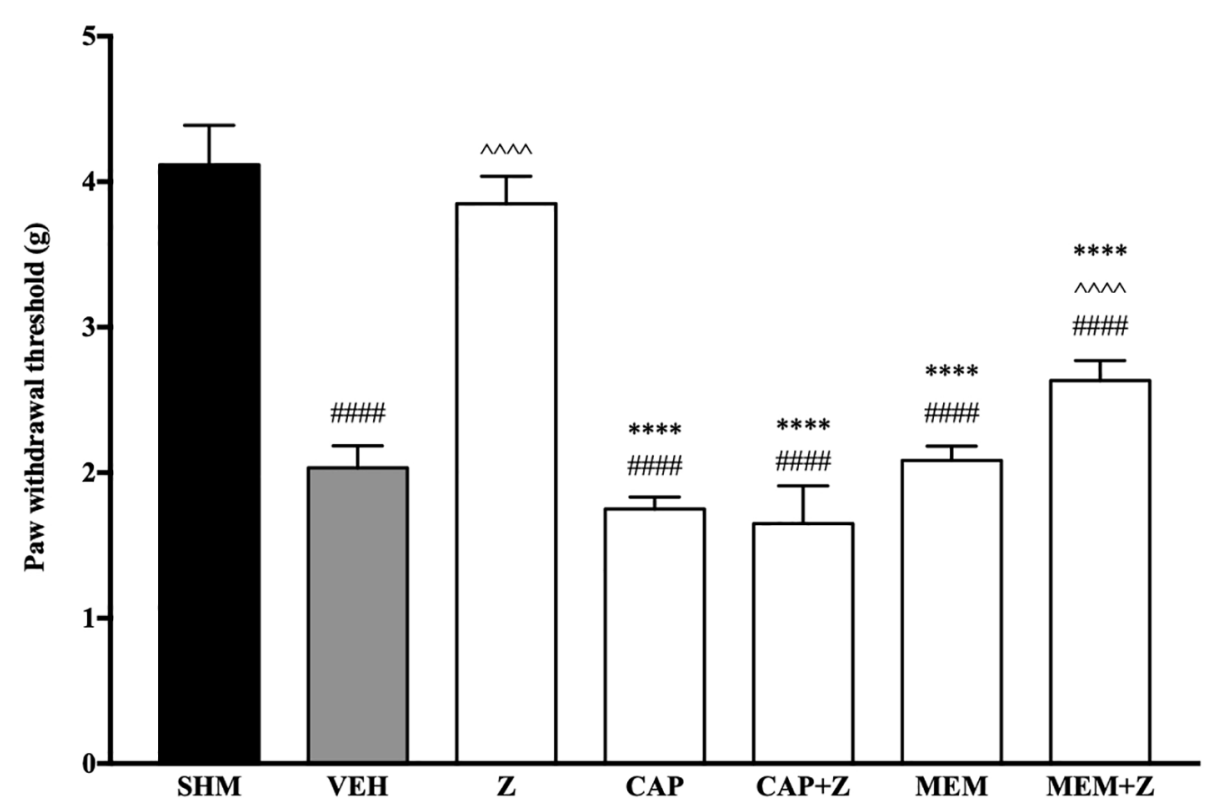

FIGURE 8 | Effect of capsazepine (TRPV1 antagonist) and memantine (NMDA antagonist) pre-treatment on zerumbone against mechanical allodynia in CCl-induced neuropathic pain mice. Data are presented as mean \pm SEM $(n=6) .{ }^{\# \# \#} p<0.0001$ as compared to sham, ${ }^{\wedge \wedge \wedge} p<0.0001$ as compared to vehicle and ${ }^{\star \star \star \star} p<$ 0.0001 as compared to zerumbone-treated group. SHM (Sham); VEH (Vehicle, $10 \mathrm{~mL} / \mathrm{kg}$ i.p.); Z (Zerumbone, 10 mg/kg i.p.); CAP (Capsazepine, $10 \mathrm{mg} / \mathrm{kg}$ i.p.); MEM (Memantine, $10 \mathrm{mg} / \mathrm{kg}$ i.p.). 


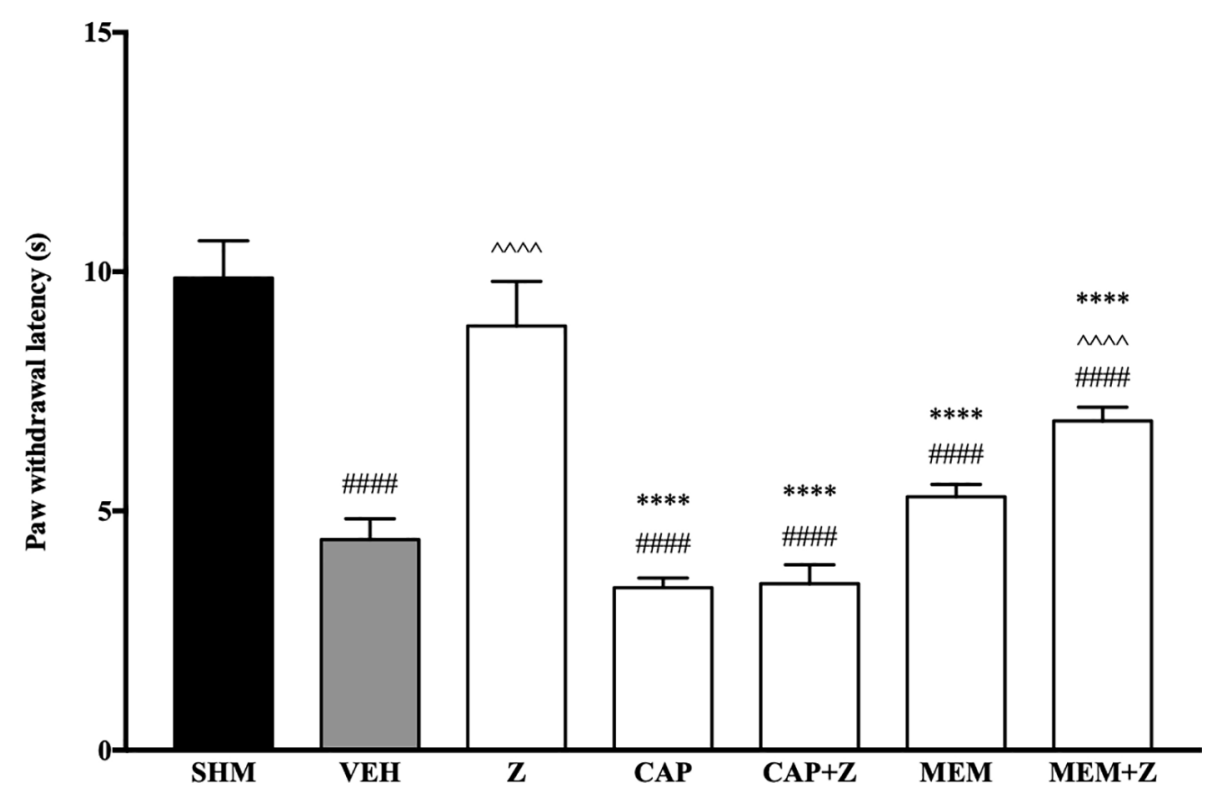

FIGURE 9 | Effect of capsazepine (TRPV1 antagonist) and memantine (NMDA antagonist) pre-treatment on zerumbone against thermal hyperalgesia in CCI-induced

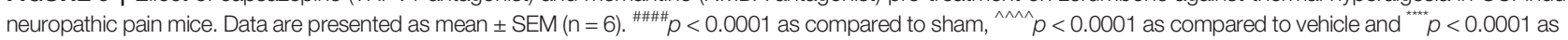
compared to zerumbone-treated group. SHM (Sham); VEH (Vehicle, $10 \mathrm{~mL} / \mathrm{kg}$ i.p.); Z (Zerumbone, $10 \mathrm{mg} / \mathrm{kg}$ i.p.); CAP (Capsazepine, 10 mg/kg i.p.); MEM (Memantine, $10 \mathrm{mg} / \mathrm{kg}$ i.p.).

\section{TRPV1}

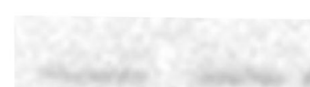

4

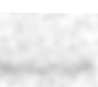

$94 \mathrm{kDa}$

$42 \mathrm{kDa}$

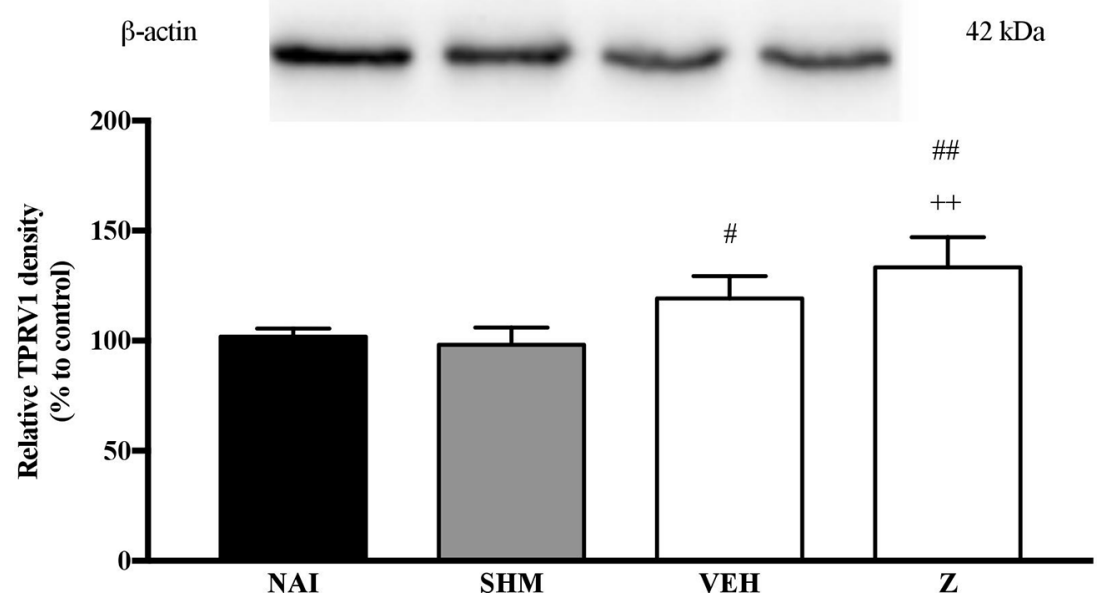

FIGURE 10 | Representative western blots of TRPV1 receptor from brain samples of naïve, sham, vehicle and zerumbone-treated groups. Data presented as mean \pm SEM $(n=4)$, which were normalized to $\beta$-actin. ${ }^{++} p<0.01$ as compared to naïve and ${ }^{\#} p<0.05$, ${ }^{\# \#} p<0.01$ as compared to sham group. NAI (Naïve); SHM (Sham); VEH (Vehicle, $10 \mathrm{~mL} / \mathrm{kg}$ ); Z (Zerumbone, $10 \mathrm{mg} / \mathrm{kg}$ ). 

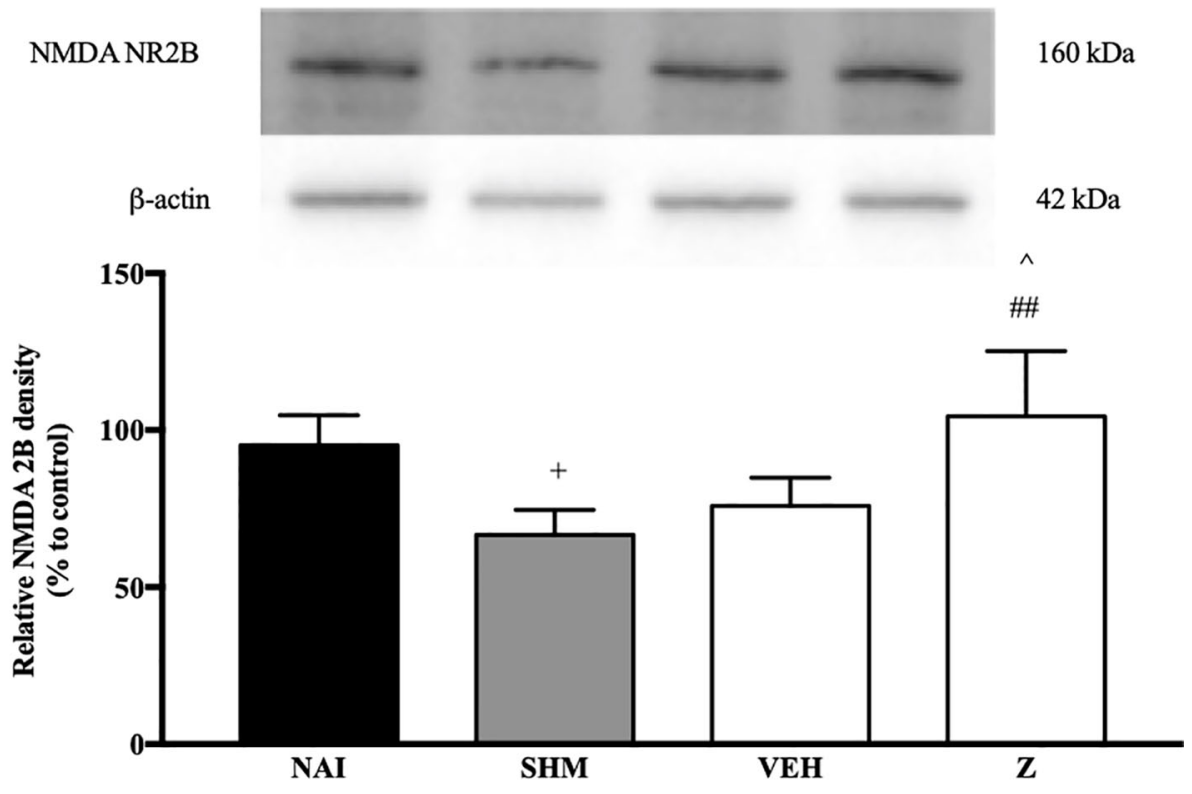

FIGURE 11 | Representative western blots of NMDA NR2B receptor from brain samples of naïve, sham, vehicle and zerumbone-treated groups. Data presented as mean $\pm \operatorname{SEM}(n=4)$, which were normalized to $\beta$-actin. ${ }^{+} p<0.05$ as compared to naïve, ${ }^{\# \#} p<0.01$ as compared to sham group and ${ }^{\wedge} p<0.05$ as compared to vehicle. NAI (Naïve); SHM (Sham); VEH (Vehicle, $10 \mathrm{~mL} / \mathrm{kg}$ ); Z (Zerumbone, $10 \mathrm{mg} / \mathrm{kg}$ ).

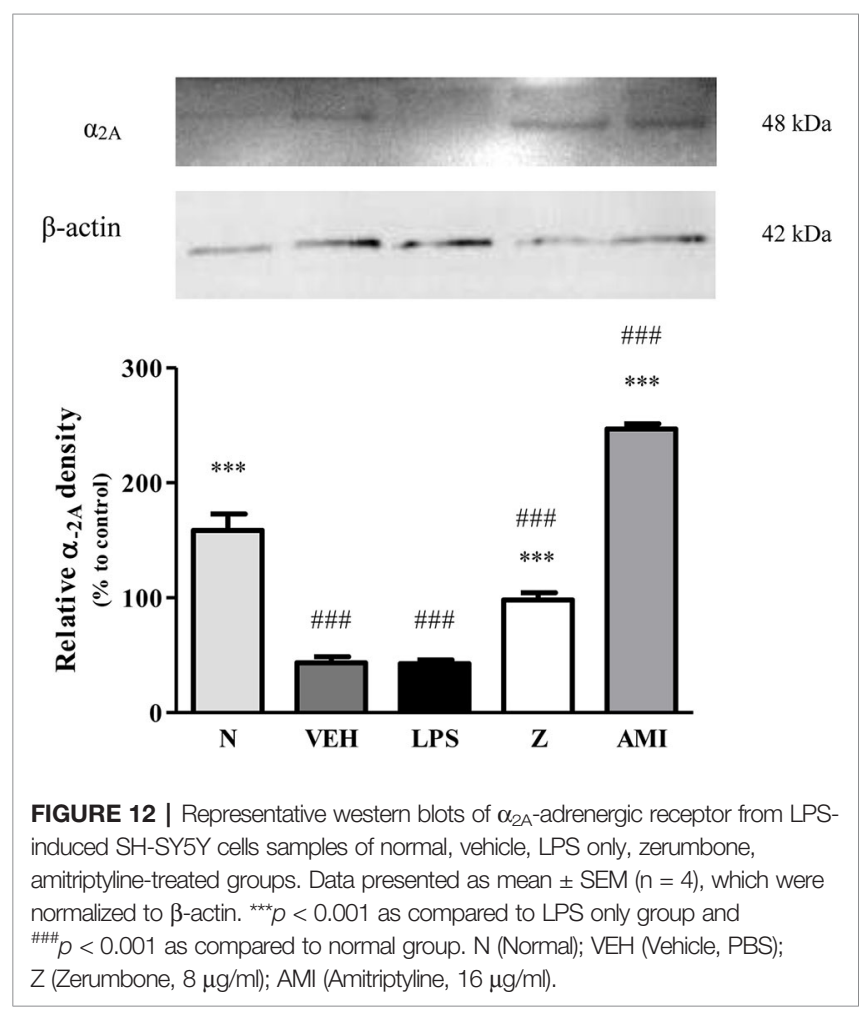

increased the expression of $\alpha_{2 \mathrm{~A}}$-adrenergic receptors by the SHSY5Y cells. In contrast, both the TRPV1 and NMDA NR2B receptors were down-regulated following the treatment with zerumbone as shown in Figures 13 and 14. Additionally, the in

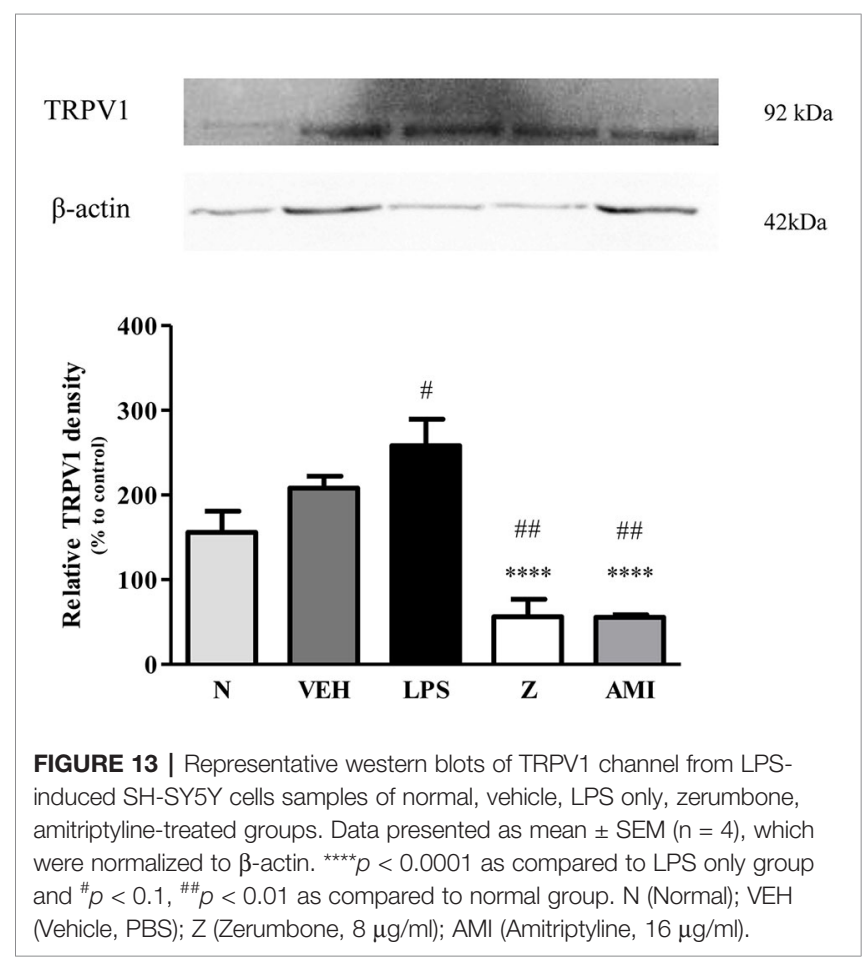

vitro findings are in contrast to the receptor's expression in the in vivo brain regions where, $\alpha_{2 \mathrm{~A}}$-adrenergic receptors were downregulated while the TRPV1 and NMDA NR2B receptors were up-regulated. 

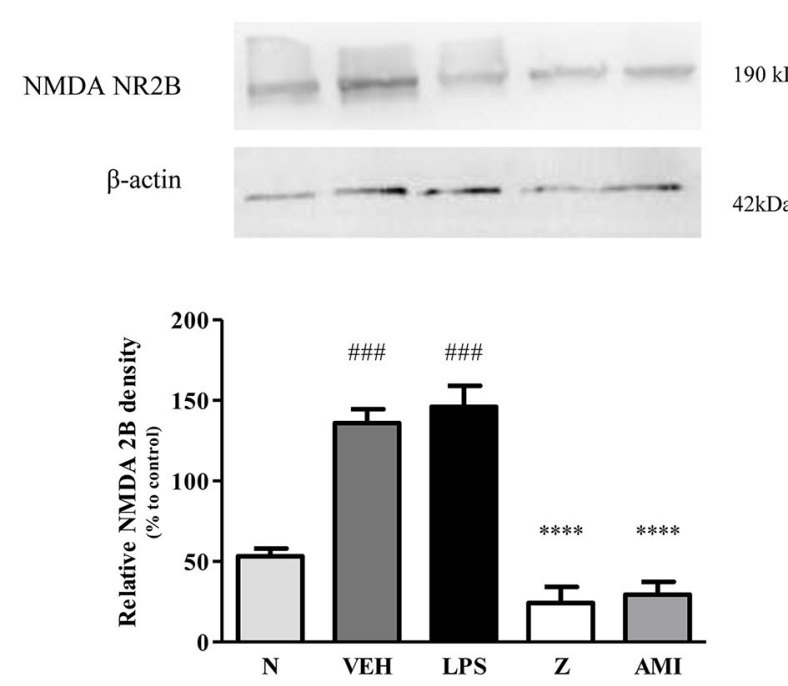

FIGURE 14 | Representative western blots of NMDA NR2B receptor from LPS-induced SH-SY5Y cells samples of normal, vehicle, LPS only, zerumbone, amitriptyline-treated groups. Data presented as mean \pm SEM (n $=4)$, which were normalized to $\beta$-actin. ${ }^{\star * \star *} p<0.0001$ as compared to LPS only group and ${ }^{\# \#} p<0.001$ as compared to normal group. N (Normal); VEH (Vehicle, PBS); Z (Zerumbone, $8 \mu \mathrm{g} / \mathrm{ml}$ ); AMl (Amitriptyline, $16 \mu \mathrm{g} / \mathrm{ml}$ ).

\section{DISCUSSION AND CONCLUSION}

We have previously demonstrated the antinociceptive properties of zerumbone in the chronic constriction injury neuropathic pain mice model and its mechanisms through serotoninergic (Chia et al., 2016) and the L-arginine-nitric oxide (Zulazmi et al., 2017) pathways. With this study, we now show that the noradrenergic system and excitatory receptors are crucial to zerumbone's anti-allodynic and antihyperalgesic properties. Our current study suggests that zerumbone produces its anti-allodynic properties by interacting with $\alpha_{1^{-}}, \alpha_{2^{-}}, \beta_{1^{-}}$, and $\beta_{2^{-} \text {-adrenergic }}$ receptors. Meanwhile, $\alpha_{1^{-}}, \alpha_{2^{-}}, \beta_{2}$-adrenergic receptors are responsible for zerumbone's antihyperalgesic property. Excitatory receptors TRPV and NMDA are involved in both zerumboneinduced anti-allodynia and antihyperalgesia. Therefore, we hypothesize that a synergistic mechanism between noradrenaline, TRPV, and NMDA is utilized by zerumbone to produce its antiallodynic and antihyperalgesic properties.

The noradrenergic system is part of the descending monoaminergic pain modulation pathway. The serotonergic system is known to exert both inhibitory as well as excitatory effects in pain modulation, whereas the noradrenergic system predominantly has an inhibitory role in pain modulation (Suzuki et al., 2004b). Two main classes of adrenergic receptors (AR) arise from the noradrenergic projections from the locus coeruleus (LC), which are the $\alpha$ and $\beta$ ARs (Millan, 2002; Hentall et al., 2003). Both $\alpha$ and $\beta$ ARs and their subtypes are $\mathrm{G}$ protein-coupled receptors (GPCR), thus their main action after binding of noradrenaline differs depending on the sub-class of $\mathrm{G}$ proteins each receptor couples to (Llorca-Torralba et al., 2016).

Following nerve injury, the central and peripheral nervous system undergoes physiological changes. Possible alterations to descending monoaminergic pathway influences neurotransmitter metabolism and/or number and affinity of receptor uptake sites lead to neuropathic pain (Suzuki et al., 2004a; Rahman et al., 2008; Leong et al., 2011). The induction of neuropathic pain was measured by the endurance of the animals through behavioral tests on their pain threshold. Firstly, we investigated the involvement of noradrenergic receptors by administering non-selective $\alpha$ - and $\beta$-adrenoceptor antagonists, phentolamine and propranolol respectively. In the presence of phentolamine and propranolol, both the antiallodynic and antihyperalgesic properties of zerumbone we attenuated. Thus, further examinations into specific receptors to the noradrenergic system were conducted.

Administration of prazosin, a selective $\alpha_{1}$-AR antagonist prior to zerumbone treatment managed to abolish zerumbone's anti-neuropathic properties. The $\alpha_{1}$ adrenoceptors are $G_{q / 11}$ protein receptors, which are coupled to phospholipase C (PLC) (Bylund et al., 1994). Binding of noradrenaline to $\alpha_{1}$-AR causes increase in intracellular calcium pool as a result of hydrolysis of inositol phosphates, with diacyl glycerol (DAG) and inositol triphosphate $\left(\mathrm{IP}_{3}\right)$ as its products (Millan, 2002). The $\alpha_{1}$-AR has been implicated to facilitate nociception (Millan, 1999; Fuchs et al., 2001; Hord et al., 2001b), and is said to contribute to the development of chronic pain. However, previous studies have reported antinociceptive activity when $\alpha_{1}$-AR agonists were used, possibly acting pre-synaptically on central primary afferent nociceptors (Howe et al., 1983; Kawabata et al., 1994; Hord et al., 2001a). As discussed by Millan (2002), the bidirectional reports on both pro- and anti-nociceptive effects of $\alpha_{1}$-AR could be due to co-localization of $\alpha_{1}$ - and $\alpha_{2}$-AR.

As with the $\alpha_{1}$-AR antagonist, the anti-allodynic and antihyperalgesic properties of zerumbone were absent when $\alpha_{2}$-AR antagonist, idazoxan, was administered prior to zerumbone treatment. Unlike $\alpha_{1}$-AR, $\alpha_{2}$-adrenoceptors are coupled to $G_{i / o}$ proteins, which alters membrane polarization through $\mathrm{K}^{+}$and $\mathrm{Ca}^{2+}$ channels (Millan, 2002). Activation of $\alpha_{2}-$ AR results in intracellular changes whereby cAMP levels are decreased due to inhibition of adenylyl cyclase. The $\alpha_{2}$-AR is the most commonly implicated adrenergic receptor to be responsible in inhibiting pain transmission. Pre-synaptically, the $\alpha_{2}$-AR plays an important inhibitory feedback mechanism in the release of noradrenaline from adrenergic neurons (Gilsbach and Hein, 2008). There are three subtypes to $\alpha_{2}-A R$, which are the $2 \mathrm{~A}, 2 \mathrm{~B}$, and $2 \mathrm{C}$ receptor subtypes. $\alpha_{2 \mathrm{~A}^{-}}$and $\alpha_{2 \mathrm{C}^{-}} \mathrm{AR}$ are widely expressed in the central nervous system (CNS) while the $\alpha_{2 \mathrm{~B}}$-AR can be commonly found in non-neuronal tissues. The $\alpha_{2 \mathrm{~A}}-\mathrm{AR}$ is the predominant subtype found in the brainstem.

Based on the results obtained in the present study, zerumbone utilizes the $\alpha_{2}$-AR in exhibiting its anti-neuropathic effect. Activation of $\alpha_{2}$-AR causes an increase in neuronal firing activity from the LC and studies have found that activation from a $\alpha_{2}-A R$ agonist to decrease noradrenaline (NA) concentration in the 
prefrontal cortex (PFC) (Svensson et al., 1975; Pudovkina et al., 2001; Jedema et al., 2008). However, previous studies have reported that the inhibitory actions of $\alpha_{2}$-AR to be absent in neuropathic conditions (Xu et al., 2000; Obata et al., 2005; Omiya et al., 2008; Chen et al., 2011). Thus, the antinociceptive activity due to $\alpha_{2}$-AR activation is said to originate from the LC, to compensate in the loss of spinal $\alpha_{2}$-adrenergic receptor activity. Alternatively, AlbaDelgado et al. (2012) has proposed that $\alpha_{2}$-AR desensitization to occur in the LC that enhances the antinociceptive noradrenergic effects in neuropathic pain conditions.

$\beta$-adrenoceptors can be further classified into $\beta_{1^{-}}, \beta_{2^{-}}$, and $\beta_{3^{-}}$ adrenergic receptors (Bylund et al., 1994). All three $\beta-A R$ are $G_{s}$ proteins, coupled to adenylyl cyclase to increase intracellular secondary messenger cAMP synthesis. These receptors are widely distributed in the CNS (Nicholas et al., 1993). Although most of the focus on the noradrenergic system is on the $\alpha_{2}$ subtype, studies have shown that $\beta$-AR are also involved in pain modulation (Brochet et al., 1986; Choucair-Jaafar et al., 2009).

The zerumbone-induced anti-allodynic and antihyperalgesic effects were significantly reversed by administration of ICI 118,551 , a $\beta_{2}$-AR antagonists, but not of SR $59230 \mathrm{~A}$, a $\beta_{3}$-AR antagonist. Metoprolol, a $\beta_{1}$-AR antagonist, only attenuated the anti-allodynic effect of zerumbone. $\beta_{1}$ - and $\beta_{2}$-AR are found in both central and peripheral nervous systems, with the $\beta_{1}$-AR densely expressed in cerebral cortex, thalamus, and sympathetic ganglia whereas $\beta_{2}$-AR to localize more in the olfactory bulb, hippocampus, hypothalamus, and spinal cord (Nicholas et al., 1996; Gilsbach and Hein, 2008). As mentioned, the $\alpha_{2}$ adrenergic receptors are the predominant adrenergic receptors to inhibit nociceptive transmission. Thus, not many studies have been conducted on $\beta$-adrenergic receptor subtypes. However, studies have shown that $\beta_{2}$-AR is necessary for antidepressants to exhibit its anti-neuropathic effects (Yalcin et al., 2009a; Yalcin et al., 2009b). It is possible that the activation of downstream proteins due to $\beta_{2}$-AR facilitates protein kinase A activation by cAMP, which results in enhanced NA release from sympathetic nerves (Boehm and Kubista, 2002; Kubista and Boehm, 2006).

With consideration to our current findings and in line with literature on the more prominent role of $\alpha_{2}$-adrenergic receptors, primarily the $\alpha_{2 \mathrm{~A}}$ subtype, we investigated whether the $\alpha_{2 \mathrm{~A}^{-}}$ adrenoceptor is involved in zerumbone's anti-neuropathic effects. Our findings have shown (Figure 7) that chronic constriction injury induces an increase in expression of $\alpha_{2 A^{-}}$ adrenergic receptors in the brain. Previous studies have also reported similar findings, where nerve lesions causes an upregulation in $\alpha_{2 \mathrm{~A}}$-adrenergic receptor expression as early as 7 days following injury induction (Alba-Delgado et al., 2013).

In normal conditions, the noradrenergic system primarily functions to inhibit nociceptive transmission. Following nerve injury, the plastic changes that occur shift the inhibitory tone of the noradrenergic system to facilitate nociceptive transmission instead (Brightwell and Taylor, 2009; Kaushal et al., 2016). Therefore, the increase in expression of $\alpha_{2 \mathrm{~A}}$-adrenoceptor following CCI in vehicle-treated group may be due to plastic changes that occur, abolishing the inhibitory tone of the noradrenergic system. In support of this hypothesis, zerumbone treatment suppressed the increased expression of $\alpha_{2 \mathrm{~A}}-\mathrm{AR}$ as shown in this study. Development of neuropathic pain is the result of cumulative plastic changes that occur throughout the nervous system. Our findings as shown in Figure 7 indicates that the expression of $\alpha_{2 \mathrm{~A}}$-AR decreases upon zerumbone administration. It is possible that the primary action of zerumbone in attenuating allodynia and hyperalgesia is through suppression of the $\alpha_{2 \mathrm{~A}}$-AR up-regulation.

Therefore, the cumulative action of zerumbone against neuropathic pain might not only utilize the descending noradrenergic pathway, but also through the noradrenergic projections to the other brain sites involved in the pain pathway. In particular, the rostroventromedial medulla and periaqueductal gray brain regions are important in modulating nociceptive signals (Pertovaara, 2006). Moreover, adrenoceptors are also localized on the descending serotonergic pathway. The inhibitory $\alpha_{2}$-AR especially, has been reported to be highly concentrated in serotonergic neurons (Rosin et al., 1993; Guyenet et al., 1994; Millan et al., 2000; Millan, 2002).

Our current findings implicate the involvement of TRPV1 and NMDA NR2B receptors in zerumbone's anti-allodynic and antihyperalgesic properties. Zerumbone and the essential oil of Zingiber zerumbet have been associated with TRPV and glutamatergic (NMDA) system in its mechanistic actions against acute pain (Khalid et al., 2011; Perimal et al., 2011). Due to similarities between acute and chronic pain pathways, zerumbone is therefore implicated to also involve TRPV and NMDA receptors in exerting its anti-neuropathic properties in the CCI model of neuropathic pain.

The families of transient receptor potential (TRP) ion channels are primarily expressed on nociceptive neurons. TRPV1 receptors in particular, were discovered to be involved in nociceptive processing due to capsaicin, an active component from Capsicum chili peppers (Caterina et al., 1997). Acidic conditions, high temperatures, and noxious stimuli activate TRPV1 receptors. In the pathogenesis of neuropathic pain, expression of TRPV1 is up-regulated on uninjured A- and Cfibers, as well as injured dorsal root ganglions. These alterations to receptor expression causes an amplification of noxious stimuli resulting in peripheral sensitization (Baron, 2006).

Zerumbone is hypothesized to exert either an antagonist-like effect or desensitize TRPV1 receptors to suppress mechanical allodynia and thermal hyperalgesia. Previous studies have reported that TRPV1 antagonists are able to alleviate nociception. Yamamoto et al. (2008) reported the TRPV1 antagonist, $\mathrm{N}$-(4-Tertiarybutylphenyl)-4-(3-chloropyridin-2-yl) tetrahydropyrazine-1(2H)-carbox-amide (BCTC), suppressed mechanical allodynia in the CCI neuropathic pain model. As a relative comparison to zerumbone, curcumin has also exhibited potent analgesic properties (Sharma et al., 2006; Mittal et al., 2009; Zhao et al., 2014). Curcumin, the active ingredient of turmeric (Curcuma longa), with several of its analogues behave as antagonists on TRP channels (Nalli et al., 2017). Similarly, Yeon et al. (2010) observed suppression of TRPV activation by curcumin, thereby exhibiting antihyperalgesic effect.

On the contrary, zerumbone could also act as an agonist to desensitize TRPV receptors. Similar mechanisms can be observed with capsaicin, a TRPV agonist. Many over-the- 
counter topical creams contain low concentrations of capsaicin, typically used as an analgesic. Analgesia produced from TRPV activation occurs due to the lasting refractory rate. This desensitization phase causes the excitable receptors to be insensitive to any noxious stimuli (Perry et al., 2007). Among the ligands that are able to activate the TRPV1 channels are vanilloids (e.g.: resineferatoxin, capsaicin), protons, endogenous lipids, polyamines, and noxious heat (Caterina et al., 1997; Zygmunt et al., 1999; Ahern et al., 2005; Ahern et al., 2006).

The noradrenergic system and TRPV receptors have shown their interrelation in the pain pathway. Our findings show zerumbone utilizes noradrenergic receptors as well as TRPV receptors in eliciting its anti-neuropathic properties. Recently, Chakraborty et al. (2017) found that noradrenaline released via the descending noradrenergic system inhibits pre-synaptic TRPV1 channels. Therefore, it is possible that the descending noradrenergic system enhances the inhibition on TRPV1 channels in the presence of zerumbone to attenuate neuropathic pain symptoms.

Further analysis into expression of TRPV1 receptors on mice in neuropathic pain conditions shows a significant increase. The present findings observed a slight increase in TRPV1 expression in comparison to neuropathic pain mice. An up-regulation in TRPV receptor expression has been reported. On the basis of their known mechanisms, the increase in expression of the excitatory receptor TRPV1 is therefore implicated in the enhanced excitability state of nociceptive transmission. As a result, the peripheral sensitization that occurs soon develops to neuropathic pain (Mannion et al., 1999; Ji et al., 2002).

Expression of TRPV1 in brain is primarily in microglial cells and in discrete amounts at other brain regions such as anterior cingulate cortex (ACC). TRPV1 activation modulates synaptic neurotransmission and indirectly enhances glutamatergic neuronal transmission, heightening nociceptive transmission leading to pathophysiological persistence of pain (Marrone et al., 2017). However, recent advances by Silva et al. (2016) have also provided new evidences in the inhibitory influence of TRPV1 channels in modulating nociceptive transmission. The modulatory role is reportedly controlled by the expression of TRPV1 on the rostral ventromedial medulla (RVM), in contrast to ACC region mentioned earlier. Therefore, the inhibitory role of TRPV1 up-regulation from zerumbone treatment is possibly implicated by its modulatory role expressed by TRPV1 in the RVM.

NMDA is an ionotropic glutamate receptor. NMDA receptors bind to glutamate, the major excitatory neurotransmitter of the central nervous system. Glutamate and its receptors are the major contributors to the development of neuropathic pain through central sensitization (Bennett, 2000). Activation of this class of excitatory receptors causes an influx of $\mathrm{Ca}^{2+}$, activation of nitric oxide synthases (NOS) and cyclooxygenase-2 (COX-2). The disproportionate availability of nitric oxide and prostaglandin results in prolonged excitation of neural and glial cells (Fundytus, 2001).

The present study shows that zerumbone partially utilizes NMDA receptors to elicit its anti-allodynic and antihyperalgesic effects. These results conform to previous study on zerumbone in an animal model of acute pain where zerumbone dosedependently inhibited glutamate-induced nociception (Perimal et al., 2011). Considering the excitatory functioning on NMDA receptors, antagonists to these receptors are now considered as clinical analgesics. Zerumbone is therefore postulated to act as an antagonist on NMDA receptors, thus suppressing calcium ions influx to dampen nociceptive transmission. The action of zerumbone on glutamatergic transmission may occur either peripherally or centrally.

Several populations of glutamatergic receptors, including NMDA, are known to localize on noradrenergic terminals. Presynaptic activation these NMDA receptors regulates the release of NA (Forray et al., 2000; Luccini et al., 2007). Increased availability of NA thus enhances the inhibitory tone of the noradrenergic system. A vice versa mechanisms have also been reported, where activation of the locus coeruleus noradrenergic system causes a down-regulation of NMDA receptors (Roh et al., 2008; Kang et al., 2012). Therefore, our current findings imply that the mechanistic action of zerumbone is not specific to a single pathway, but rather a summative effect through various inhibitory and excitatory receptors.

The NMDA NR2B subunit was chosen to further analyze the effects of zerumbone. Activation of NR2B subunit contributes to the excitatory role of NMDA receptors as it induces c-Jun $\mathrm{N}$-terminal kinase (JNK) activation and enhances astrocyticneuronal signaling (Kato et al., 2006). The NR2B subunit of NMDA receptors are regionally distributed, however it is primarily expressed superficially at the dorsal horn and is highly associated with nociceptive transmission (Laurie et al., 1997). In the present study, it was found that expression of NMDA NR2B in CCI mice did not significantly increase in comparison to naïve and sham groups. On the contrary, zerumbone-treated groups presented a significantly increased expression in comparison to sham and vehicle groups.

Over-expression of NMDA NR2B subunit has also been reported in the brain and spinal cord in chronic pain conditions (Tang et al., 1999; Wei et al., 2002). The increased expression of NR2B subunit is linked to inflammation leading up to persistent pain, where its over-expression was observed in the ACC in the Complete Freund's Adjuvant chronic inflammatory animal model (Wu et al., 2005). The use of CCI model as well as whole brain sample could be a possible rationalization to the insignificant change in NMDA NR2B subunit observed in this study. Furthermore, previous studies have reported a downregulation of the NR2B subunit in analgesic compounds ( $\mathrm{Hu}$ et al., 2009; Wang et al., 2013). It is reasonable to hypothesize that the up-regulation observed in zerumbone-treated groups is due to the acute administration of treatment- which may not be sufficient to cause any effect of NR2B expression in the brain. Possibility of a modulatory action of NR2B subunit upregulation should be further explored.

It is interesting to note that the expression of $\alpha_{2 \mathrm{~A}}$-AR was upregulated while both the TRPV1 and NMDA NR2B receptors were down-regulated respectively in the in vitro SH-SY5Y neuroblastoma cell model. These findings are coherent with 
both the behavioral allodynia and hyperalgesia assays. We note that the etiology of neuropathic pain is complex, and in some cases findings are contradictory (Lee et al., 2013) and left unexplained, however in this case, we postulate that zerumbone interacts and possibly triggers modulation differently in the peripheral nervous system compared to the central nervous system. As we have explained the proposed mechanisms in the brain regions explicitly in the preceding paragraphs, we can only conclude that in the peripheral nervous system, zerumbone acts as an agonist for the $\alpha_{2 A^{-}}$ adrenoceptor (Kimura et al., 2012), and modulates both the TRPV1 (Perry et al., 2007; Yamamoto et al., 2008) and NMDA NR2B (Hu et al., 2009; Wang et al., 2013) receptors. These receptors and pathways are well established and studied.

Our findings on the expression of $\alpha_{2 \mathrm{~A}}$-adrenoceptor, TRPV1 and NMDA NR2B receptors at the brain regions complemented by the exact opposite on the in vitro model further reiterated the plasticity of neuronal signaling in pain and the nervous system. While we know that the dorsal horn is one of the first point for pain signal transmission, a huge body of literature is now pointing to the relevance of the descending control of the nervous system in further regulating and modulating pain signals both ascending and descending. Interestingly, they can be both facilitatory or inhibitory or both (Heinricher et al., 2009).

In conclusion, our findings indicate the interaction between the noradrenergic system, TRPV1, NMDA receptors, and zerumbone in exhibiting anti-allodynic and antihyperalgesic effects in a neuropathic pain mice model. Moreover, the action of zerumbone on $\alpha_{2 \mathrm{~A}}$-adrenoceptor, TRPV1 and NMDA NR2B receptor expression provides significant information on the mechanism of action of zerumbone. In support with previous studies on zerumbone against neuropathic pain, zerumbone has high potential as an antinociceptive compound for treatment of neuropathic pain. Research into new and better treatments for neuropathic pain patients are in critical need. A combinatorial therapy approach, consisting of drugs with different mechanisms of action, is currently used to treat neuropathic pain patients. Future research into the effect of zerumbone, in both chronic and acute treatments, on the relationship between various pain modulatory pathways in neuropathic pain models should be conducted.

\section{REFERENCES}

Ahern, G. P., Brooks, I. M., Miyares, R. L., and Wang, X. B. (2005). Extracellular cations sensitize and gate capsaicin receptor TRPV1 modulating pain signaling. J. Neurosci. 25 (21), 5109-5116. doi: 10.1523/jneurosci.0237-05.2005

Ahern, G. P., Wang, X., and Miyares, R. L. (2006). Polyamines are potent ligands for the capsaicin receptor TRPV1. J. Biol. Chem. 281 (13), 8991-8995. doi: 10.1074/jbc.M513429200

Alba-Delgado, C., Borges, G., Sanchez-Blazquez, P., Ortega, J. E., Horrillo, I., Mico, J. A., et al. (2012). The function of alpha-2-adrenoceptors in the rat locus coeruleus is preserved in the chronic constriction injury model of neuropathic pain. Psychopharmacol. (Berl) 221 (1), 53-65. doi: 10.1007/ s00213-011-2542-7

Alba-Delgado, C., Llorca-Torralba, M., Horrillo, I., Ortega, J. E., Mico, J. A., Sánchez-Blázquez, P., et al. (2013). Chronic pain leads to concomitant

\section{DATA AVAILABILITY STATEMENT}

The datasets used and/or analysed for this manuscript are available from the corresponding author on reasonable request.

\section{ETHICS STATEMENT}

The animal study was reviewed and approved by the Institutional Animal Care and Use Committee (IACUC) UPM (Ref: UPM/ IACUC/AUP- R060/2013).

\section{AUTHOR CONTRIBUTIONS}

All authors equally contributed to the study and critically reviewed the final version of the manuscript

\section{FUNDING}

This study was supported by the Putra Grant-Putra Graduate Initiative (GP-IPS/2017/9528400), the Putra Grant-High Performance Research Grant (GPB-9659000) from Universiti Putra Malaysia and the Science Fund Scheme (Grant No: 5450778) under the Ministry of Science, Technology \& Innovation Malaysia.

\section{ACKNOWLEDGMENTS}

The authors would like to thank the Faculty of Medicine and Health Sciences, the Physiology Research Laboratory, Universiti Putra Malaysia, Malaysia and the Australian Research Council Centre of Excellence for Nanoscale BioPhotonics, The University of Adelaide, Australia for providing the necessary support for this study.

\section{SUPPLEMENTARY MATERIAL}

The Supplementary Material for this article can be found online at: https://www.frontiersin.org/articles/10.3389/fphar.2020. 00092/full\#supplementary-material

noradrenergic impairment and mood disorders. Biol. Psychiatry 73 (1), 5462. doi: 10.1016/j.biopsych.2012.06.033

Anand, P., and Bley, K. (2011). Topical capsaicin for pain management: therapeutic potential and mechanisms of action of the new highconcentration capsaicin 8\% patch. Br. J. Anaesth. 107 (4), 490-502. doi: 10.1093/bja/aer260

Bajic, D., and Proudfit, H. K. (1999). Projections of neurons in the periaqueductal gray to pontine and medullary catecholamine cell groups involved in the modulation of nociception. J. Comp. Neurol. 405 (3), 359-379. doi: 10.1002/ (SICI)1096-9861(19990315)405:3<359::AID-CNE6>3.0.CO;2-W

Bannister, K., and Dickenson, A. H. (2016). What do monoamines do in pain modulation? Curr. Opin. Support. Palliat. Care 10 (2), 143-148. doi: 10.1097/ SPC.0000000000000207

Baron, R., and Tolle, T. R. (2008). Assessment and diagnosis of neuropathic pain. Curr. Opin. Support. Palliat. Care 2 (1), 1-8. doi: 10.1097/SPC.0b013e3282f57da5 
Baron, R. (2006). Mechanisms of disease: neuropathic pain-a clinical perspective. Nat. Rev. Neurol. 2 (2), 95-106. doi: 10.1038/ncpneuro0113

Basbaum, A. I., and Fields, H. L. (1978). Endogenous pain control mechanisms: review and hypothesis. Ann. Neurol. 4 (5), 451-462. doi: 10.1002/ana.410040511

Bennett, G. J., and Xie, Y. K. (1988). A peripheral mononeuropathy in rat that produces disorders of pain sensation like those seen in man. Pain 33 (1), 87107. doi: 10.1016/0304-3959(88)90209-6

Bennett, G. J. (2000). Update on the neurophysiology of pain transmission and modulation: focus on the NMDA-receptor. J. Pain Symptom Manage. 19 (1 Suppl), S2-S6. doi: 10.1016/S0885-3924(99)00120-7

Boehm, S., and Kubista, H. (2002). Fine tuning of sympathetic transmitter release via ionotropic and metabotropic presynaptic receptors. Pharmacol. Rev. 54 (1), 43-99. doi: 10.1124/pr.54.1.43

Brightwell, J. J., and Taylor, B. K. (2009). Noradrenergic neurons in the locus coeruleus contribute to neuropathic pain. Neuroscience 160 (1), 174-185. doi: 10.1016/j.neuroscience.2009.02.023

Brochet, D., Mico, J. A., Martin, P., and Simon, P. (1986). Antinociceptive activity of beta-adrenoceptor agonists in the hot plate test in mice. Psychopharmacol. (Berl) 88 (4), 527-528. doi: 10.1007/BF00178520

Bruinstroop, E., Cano, G., Vanderhorst, V. G., Cavalcante, J. C., Wirth, J., SenaEsteves, M., et al. (2012). Spinal projections of the A5, A6 (locus coeruleus), and A7 noradrenergic cell groups in rats. J. Comp. Neurol. 520 (9), 1985-2001. doi: $10.1002 / \mathrm{cne} .23024$

Bylund, D. B., Eikenberg, D. C., Hieble, J. P., Langer, S. Z., Lefkowitz, R. J., Minneman, K. P., et al. (1994). International Union of Pharmacology nomenclature of adrenoceptors. Pharmacol. Rev. 46 (2), 121-136.

Caterina, M. J., Schumacher, M. A., Tominaga, M., Rosen, T. A., Levine, J. D., and Julius, D. (1997). The capsaicin receptor: a heat-activated ion channel in the pain pathway. Nature 389 (6653), 816-824. doi: 10.1038/39807

Chakraborty, S., Elvezio, V., Kaczocha, M., Rebecchi, M., and Puopolo, M. (2017). Presynaptic inhibition of transient receptor potential vanilloid type 1 (TRPV1) receptors by noradrenaline in nociceptive neurons. J. Physiol. 595 (8), 26392660. doi: $10.1113 / \mathrm{JP} 273455$

Chaplan, S. R., Bach, F. W., Pogrel, J. W., Chung, J. M., and Yaksh, T. L. (1994). Quantitative assessment of tactile allodynia in the rat paw. J. Neurosci. Methods 53 (1), 55-63. doi: 10.1016/0165-0270(94)90144-9

Chen, S. R., Chen, H., Yuan, W. X., and Pan, H. L. (2011). Increased presynaptic and postsynaptic alpha2-adrenoceptor activity in the spinal dorsal horn in painful diabetic neuropathy. J. Pharmacol. Exp. Ther. 337 (1), 285-292. doi: 10.1124/jpet.110.176586

Chia, J. S., Omar Farouk, A. A., Mohamad, A. S., Sulaiman, M. R., and Perimal, E. K. (2016). Zerumbone alleviates chronic constriction injury-induced allodynia and hyperalgesia through serotonin 5-HT receptors. BioMed. Pharmacother. 83, 13031310. doi: 10.1016/j.biopha.2016.08.052

Chien, T., Chen, L., Lee, C., Lee, F., and Wang, C. (2008). Anti-inflammatory constituents of Zingiber zerumbet. Food Chem. 110 (3), 584-589. doi: 10.1016/ j.foodchem.2008.02.038

Choucair-Jaafar, N., Yalcin, I., Rodeau, J. L., Waltisperger, E., Freund-Mercier, M. J., and Barrot, M. (2009). Beta2-adrenoceptor agonists alleviate neuropathic allodynia in mice after chronic treatment. Br. J. Pharmacol. 158 (7), 1683-1694. doi: 10.1111/ j.1476-5381.2009.00510.x

Costa, B., Comelli, F., Bettoni, I., Colleoni, M., and Giagnoni, G. (2008). The endogenous fatty acid amide, palmitoylethanolamide, has anti-allodynic and anti-hyperalgesic effects in a murine model of neuropathic pain: involvement of CB(1), TRPV1 and PPARgamma receptors and neurotrophic factors. Pain 139 (3), 541-550. doi: 10.1016/j.pain.2008.06.003

Das, N. D., Choi, M. R., Jung, K. H., Park, J. H., Lee, H. T., Kim, S. H., et al. (2012). Lipopolysaccharide-mediated protein expression profiling on neuronal differentiated SH-SY5Y cells. BioChip J. 6 (2), 165-173. doi: 10.1007/s13206012-6209-1

Eisenberg, E., LaCross, S., and Strassman, A. M. (1995). The clinically tested Nmethyl-D-aspartate receptor antagonist memantine blocks and reverses thermal hyperalgesia in a rat model of painful mononeuropathy. Neurosci. Lett. 187 (1), 17-20. doi: 10.1016/0304-3940(95)11326-R

Forray, M. I., Gysling, K., Andrés, M. E., Bustos, G., and Araneda, S. (2000). Medullary noradrenergic neurons projecting to the bed nucleus of the stria terminalis express mRNA for the NMDA-NR1 receptor. Brain Res. Bull. 52 (3), 163-169. doi: 10.1016/S0361-9230(00)00229-X
Forster, J. I., Koglsberger, S., Trefois, C., Boyd, O., Baumuratov, A. S., Buck, L., et al. (2016). Characterization of differentiated SH-SY5Y as neuronal screening model reveals increased oxidative vulnerability. J. Biomol. Screen 21 (5), 496509. doi: $10.1177 / 1087057115625190$

Fuchs, P. N., Meyer, R. A., and Raja, S. N. (2001). Heat, but not mechanical hyperalgesia, following adrenergic injections in normal human skin. Pain 90 (1-2), 15-23. doi: 10.1016/S0304-3959(00)00381-X

Fundytus, M. E. (2001). Glutamate receptors and nociception: implications for the drug treatment of pain. CNS Drugs 15 (1), 29-58. doi: 10.2165/00023210200115010-00004

Gebhart, G. F. (2004). Descending modulation of pain. Neurosci. Biobehav. Rev. 27 (8), 729-737. doi: 10.1016/j.neubiorev.2003.11.008

Gilsbach, R., and Hein, L. (2008). "Presynaptic Metabotropic Receptors for Acetylcholine and Adrenaline/Noradrenaline," in Pharmacology of Neurotransmitter Release, 261-288 . Eds. T. C. Südhof and K. Starke (Berlin, Heidelberg: Springer Berlin Heidelberg).

Gopalsamy, B., Farouk, A. A. O., Tengku Mohamad, T. A. S., Sulaiman, M. R., and Perimal, E. K. (2017). Antiallodynic and antihyperalgesic activities of zerumbone via the suppression of IL-1beta, IL-6, and TNF-alpha in a mouse model of neuropathic pain. J. Pain Res. 10, 2605-2619. doi: 10.2147/ JPR.S143024

Gopalsamy, B., Sambasevam, Y., Zulazmi, N. A., Chia, J. S. M., Farouk, A. A. O., Sulaiman, M. R., et al. (2019). Experimental characterization of the chronic constriction injury-induced neuropathic pain model in mice. Neurochem. Res. 44 (9), 2123-2138. doi: 10.1007/s11064-019-02850-0

Guyenet, P. G., Stornetta, R. L., Riley, T., Norton, F. R., Rosin, D. L., and Lynch, K. R. (1994). Alpha 2A-adrenergic receptors are present in lower brainstem catecholaminergic and serotonergic neurons innervating spinal cord. Brain Res. 638 (1-2), 285-294. doi: 10.1016/0006-8993(94)90661-0

Habsah, M., Amran, M., Mackeen, M., Lajis, N., Kikuzaki, H., Nakatani, N., et al. (2000). Screening of Zingiberaceae extracts for antimicrobial and antioxidant activities. J. Ethnopharmacol. 72 (3), 403-410. doi: 10.1016/S0378-8741(00) 00223-3

Hargreaves, K., Dubner, R., Brown, F., Flores, C., and Joris, J. (1988). A new and sensitive method for measuring thermal nociception in cutaneous hyperalgesia. Pain 32 (1), 77-88. doi: 10.1016/0304-3959(88)90026-7

Heinricher, M., Tavares, I., Leith, J., and Lumb, B. (2009). Descending control of nociception: specificity, recruitment and plasticity. Brain Res. Rev. 60 (1), $214-$ 225. doi: 10.1016/j.brainresrev.2008.12.009

Hentall, I. D., Mesigil, R., Pinzon, A., and Noga, B. R. (2003). Temporal and spatial profiles of pontine-evoked monoamine release in the rat9s spinal cord. $J$. Neurophysiol. 89 (6), 2943-2951. doi: 10.1152/jn.00608.2002

Holden, J. E., and Proudfit, H. K. (1998). Enkephalin neurons that project to the A7 catecholamine cell group are located in nuclei that modulate nociception: ventromedial medulla. Neuroscience 83 (3), 929-947. doi: 10.1016/S0306-4522 (97)00437-5

Hord, A. H., Chalfoun, A. G., Denson, D. D., and Azevedo, M. I. (2001a). Systemic tizanidine hydrochloride (Zanaflex) relieves thermal hyperalgesia in rats with an experimental mononeuropathy. Anesth. Analg. 93 (5), 1310-1315. doi: 10.1097/00000539-200111000-00057

Hord, A. H., Denson, D. D., Stowe, B., and Haygood, R. M. (2001b). alpha-1 and alpha-2 Adrenergic antagonists relieve thermal hyperalgesia in experimental mononeuropathy from chronic constriction injury. Anesth. Analg. 92 (6), 1558-1562. doi: 10.1097/00000539-200106000-00042

Howe, J. R., Wang, J. Y., and Yaksh, T. L. (1983). Selective antagonism of the antinociceptive effect of intrathecally applied alpha adrenergic agonists by intrathecal prazosin and intrathecal yohimbine. J. Pharmacol. Exp. Ther. 224 (3), $552-558$

Hu, J., Wang, Z., Guo, Y.-Y., Zhang, X.-N., Xu, Z.-H., Liu, S.-B., et al. (2009). A role of periaqueductal grey NR2B-containing NMDA receptor in mediating persistent inflammatory pain. Mol. Pain 5 (1), 71. doi: 10.1186/1744-8069-5-71

Izham, N. A. M., Chia, J. S. M., Vidyadaran, S., Sulaiman, M. R., Bharatham, B. H., and Perimal, E. K. (2018). The effect of DMEM and DMEM: F12 culture media on the growth of SH-SY5Y cells. Life Sci. Med. Biomed. 2 (3), 23. doi: 10.28916/ lsmb.2.3.2018.23

Jedema, H. P., Gold, S. J., Gonzalez-Burgos, G., Sved, A. F., Tobe, B. J., Wensel, T., et al. (2008). Chronic cold exposure increases RGS7 expression and decreases alpha(2)-autoreceptor-mediated inhibition of noradrenergic locus coeruleus 
neurons. Eur. J. Neurosci. 27 (9), 2433-2443. doi: 10.1111/j.1460-9568.2008. 06208.x

Jensen, T. S., Madsen, C. S., and Finnerup, N. B. (2009). Pharmacology and treatment of neuropathic pains. Curr. Opin. Neurol. 22 (5), 467-474. doi: 10.1097/WCO.0b013e3283311e13

Ji, R.-R., Samad, T. A., Jin, S.-X., Schmoll, R., and Woolf, C. J. (2002). p38 MAPK activation by NGF in primary sensory neurons after inflammation increases TRPV1 levels and maintains heat hyperalgesia. Neuron 36 (1), 57-68. doi: 10.1016/S0896-6273(02)00908-X

Kang, S.-Y., Roh, D.-H., Yoon, S.-Y., Moon, J.-Y., Kim, H.-W., Lee, H.-J., et al. (2012). Repetitive treatment with diluted bee venom reduces neuropathic pain via potentiation of locus coeruleus noradrenergic neuronal activity and modulation of spinal NR1 phosphorylation in rats. J. Pain 13 (2), 155-166. doi: 10.1016/j.jpain.2011.10.012

Kato, H., Narita, M., Miyatake, M., Yajima, Y., and Suzuki, T. (2006). Role of neuronal NR2B subunit-containing NMDA receptor-mediated Ca2+ influx and astrocytic activation in cultured mouse cortical neurons and astrocytes. Synapse 59 (1), 10-17. doi: 10.1002/syn.20213

Kaushal, R., Taylor, B., Jamal, A., Zhang, L., Ma, F., Donahue, R., et al. (2016). GABA-A receptor activity in the noradrenergic locus coeruleus drives trigeminal neuropathic pain in the rat; contribution of NA $\alpha 1$ receptors in the medial prefrontal cortex. Neuroscience 334, 148-159. doi: 10.1016/ j.neuroscience.2016.08.005

Kawabata, A., Kasamatsu, K., Umeda, N., and Takagi, H. (1994). The noradrenaline precursor L-threo-3,4-dihydroxyphenylserine exhibits antinociceptive activity via central alpha-adrenoceptors in the mouse. $B r$. J. Pharmacol. 111 (2), 503-508. doi: 10.1111/j.1476-5381.1994.tb14765.x

Khalid, M. H., Akhtar, M. N., Mohamad, A. S., Perimal, E. K., Akira, A., Israf, D. A., et al. (2011). Antinociceptive effect of the essential oil of Zingiber zerumbet in mice: possible mechanisms. J. Ethnopharmacol. 137 (1), 345-351. doi: 10.1016/j.jep.2011.05.043

Kimura, M., Saito, S., and Obata, H. (2012). Dexmedetomidine decreases hyperalgesia in neuropathic pain by increasing acetylcholine in the spinal cord. Neurosci. Lett. 529 (1), 70-74. doi: 10.1016/j.neulet.2012.08.008

Kubista, H., and Boehm, S. (2006). Molecular mechanisms underlying the modulation of exocytotic noradrenaline release via presynaptic receptors. Pharmacol. Ther. 112 (1), 213-242. doi: 10.1016/j.pharmthera.2006.04.005

Laurie, D. J., Bartke, I., Schoepfer, R., Naujoks, K., and Seeburg, P. H. (1997). Regional, developmental and interspecies expression of the four NMDAR2 subunits, examined using monoclonal antibodies. Mol. Brain Res. 51 (1), 2332. doi: 10.1016/S0169-328X(97)00206-4

Lee, H. G., Choi, J. I., Kim, Y. O., and Yoon, M. H. (2013). The role of alpha-2 adrenoceptor subtype in the antiallodynic effect of intraplantar dexmedetomidine in a rat spinal nerve ligation model. Neurosci. Lett. 557, 118-122. doi: 10.1016/j.neulet.2013.10.002

Leong, M. L., Gu, M., Speltz-Paiz, R., Stahura, E. I., Mottey, N., Steer, C. J., et al. (2011). Neuronal loss in the rostral ventromedial medulla in a rat model of neuropathic pain. J. Neurosci. 31 (47), 17028-17039. doi: 10.1523/ JNEUROSCI.1268-11.2011

Llorca-Torralba, M., Borges, G., Neto, F., Mico, J. A., and Berrocoso, E. (2016). Noradrenergic Locus Coeruleus pathways in pain modulation. Neuroscience 338, 93-113. doi: 10.1016/j.neuroscience.2016.05.057

Luccini, E., Musante, V., Neri, E., Bas, M. B., Severi, P., Raiteri, M., et al. (2007). Functional interactions between presynaptic NMDA receptors and metabotropic glutamate receptors co-expressed on rat and human noradrenergic terminals. Br. J. Pharmacol. 151 (7), 1087-1094. doi: 10.1038/sj.bjp.0707280

Mannion, R., Costigan, M., Decosterd, I., Amaya, F., Ma, Q.-P., Holstege, J., et al. (1999). Neurotrophins: peripherally and centrally acting modulators of tactile stimulus-induced inflammatory pain hypersensitivity. Proc. Natl. Acad. Sci. 96 (16), 9385-9390. doi: 10.1073/pnas.96.16.9385

Marrone, M. C., Morabito, A., Giustizieri, M., Chiurchiù, V., Leuti, A., Mattioli, M., et al. (2017). TRPV1 channels are critical brain inflammation detectors and neuropathic pain biomarkers in mice. Nat. Commun. 8, 15292. doi: 10.1038/ ncomms 15292

Merskey, H. E. (1986). Classification of chronic pain: descriptions of chronic pain syndromes and definitions of pain terms. Pain 3, 226.

Millan, M. J., Lejeune, F., and Gobert, A. (2000). Reciprocal autoreceptor and heteroreceptor control of serotonergic, dopaminergic and noradrenergic transmission in the frontal cortex: relevance to the actions of antidepressant agents. J. Psychopharmacol. 14 (2), 114-138. doi: 10.1177/026988110001400202

Millan, M. J. (1999). The induction of pain: an integrative review. Prog. Neurobiol. 57 (1), 1-164. doi: 10.1016/S0301-0082(98)00048-3

Millan, M. J. (2002). Descending control of pain. Prog. Neurobiol. 66 (6), 355-474. doi: 10.1016/S0301-0082(02)00009-6

Mittal, N., Joshi, R., Hota, D., and Chakrabarti, A. (2009). Evaluation of antihyperalgesic effect of curcumin on formalin-induced orofacial pain in rat. Phytother. Res. 23 (4), 507-512. doi: 10.1002/ptr.2662

Murakami, A., Takahashi, M., Jiwajinda, S., Koshimizu, K., and Ohigashi, H. (1999). Identification of zerumbone in Zingiber zerumbet Smith as a potent inhibitor of 12O-tetradecanoylphorbol-13-acetate-induced Epstein-Barr virus activation. Biosci. Biotechnol. Biochem. 63 (10), 1811-1812. doi: 10.1271/bbb.63.1811

Nalli, M., Ortar, G., Schiano Moriello, A., Di Marzo, V., and De Petrocellis, L. (2017). Effects of curcumin and curcumin analogues on TRP channels. Fitoterapia 122, 126-131. doi: 10.1016/j.fitote.2017.09.007

Nicholas, A. P., Pieribone, V. A., and Hokfelt, T. (1993). Cellular localization of messenger RNA for beta- 1 and beta- 2 adrenergic receptors in rat brain: an in situ hybridization study. Neuroscience 56 (4), 1023-1039. doi: 10.1016/03064522(93)90148-9

Nicholas, A. P., Hokfelt, T., and Pieribone, V. A. (1996). The distribution and significance of CNS adrenoceptors examined with in situ hybridization. Trends Pharmacol. Sci. 17 (7), 245-255. doi: 10.1016/0165-6147(96)10022-5

Obata, H., Li, X., and Eisenach, J. C. (2005). alpha2-Adrenoceptor activation by clonidine enhances stimulation-evoked acetylcholine release from spinal cord tissue after nerve ligation in rats. Anesthesiology 102 (3), 657-662. doi: 10.1097/ 00000542-200503000-00027

Omiya, Y., Yuzurihara, M., Suzuki, Y., Kase, Y., and Kono, T. (2008). Role of alpha2-adrenoceptors in enhancement of antinociceptive effect in diabetic mice. Eur. J. Pharmacol. 592 (1-3), 62-66. doi: 10.1016/j.ejphar.2008.06.087

Perimal, E. K., Akhtar, M. N., Mohamad, A. S., Khalid, M. H., Ming, O. H., Khalid, S., et al. (2011a). Zerumbone-induced antinociception: involvement of the Larginine-nitric oxide-cGMP -PKC-K+ ATP channel pathways. Basic Clin. Pharmacol. Toxicol. 108 (3), 155-162. doi: 10.1111/j.1742-7843.2010.00635.x

Perry, L., Dickau, R., Zarrillo, S., Holst, I., Pearsall, D. M., Piperno, D. R., et al. (2007). Starch fossils and the domestication and dispersal of chili peppers (Capsicum spp. L.) in the Americas. Science 315 (5814), 986-988. doi: 10.1126/science.1136914

Pertovaara, A. (2006). Noradrenergic pain modulation. Prog. Neurobiol. 80 (2), 53-83. doi: 10.1016/j.pneurobio.2006.08.001

Pertovaara, A. (2013). The noradrenergic pain regulation system: a potential target for pain therapy. Eur. J. Pharmacol. 716 (1-3), 2-7. doi: 10.1016/ j.ejphar.2013.01.067

Pudovkina, O. L., Kawahara, Y., de Vries, J., and Westerink, B. H. (2001). The release of noradrenaline in the locus coeruleus and prefrontal cortex studied with dual-probe microdialysis. Brain Res. 906 (1-2), 38-45. doi: 10.1016/ S0006-8993(01)02553-7

Rahman, W., D'Mello, R., and Dickenson, A. H. (2008). Peripheral nerve injuryinduced changes in spinal $\alpha 2$-adrenoceptor-mediated modulation of mechanically evoked dorsal horn neuronal responses. J. Pain 9 (4), 350-359. doi: 10.1016/j.jpain.2007.11.010

Roh, D.-H., Kim, H.-W., Yoon, S.-Y., Seo, H.-S., Kwon, Y.-B., Han, H.-J., et al. (2008). Intrathecal clonidine suppresses phosphorylation of the N-Methyl-Daspartate receptor NR1 subunit in spinal dorsal horn neurons of rats with neuropathic pain. Anesth. Analg. 107 (2), 693-700. doi: 10.1213/ ane.0b013e31817e 7319

Rosin, D. L., Zeng, D., Stornetta, R. L., Norton, F. R., Riley, T., Okusa, M. D., et al. (1993). Immunohistochemical localization of alpha $2 \mathrm{~A}$-adrenergic receptors in catecholaminergic and other brainstem neurons in the rat. Neuroscience 56 (1), 139-155. doi: 10.1016/0306-4522(93)90569-2

Sharma, S., Kulkarni, S. K., Agrewala, J. N., and Chopra, K. (2006). Curcumin attenuates thermal hyperalgesia in a diabetic mouse model of neuropathic pain. Eur. J. Pharmacol. 536 (3), 256-261. doi: 10.1016/j.ejphar.2006.03.006

Silva, M., Martins, D., Charrua, A., Piscitelli, F., Tavares, I., Morgado, C., et al. (2016). Endovanilloid control of pain modulation by the rostroventromedial medulla in an animal model of diabetic neuropathy. Neuropharmacology 107 49-57. doi: 10.1016/j.neuropharm.2016.03.007

Sulaiman, M., Perimal, E., Akhtar, M., Mohamad, A., Khalid, M., Tasrip, N., et al. (2010a). Anti-inflammatory effect of zerumbone on acute and chronic 
inflammation models in mice. Fitoterapia 81 (7), 855-858. doi: 10.1016/ j.fitote.2010.05.009

Sulaiman, M. R., Tengku Mohamad, T. A., Shaik Mossadeq, W. M., Moin, S., Yusof, M., Mokhtar, A. F., et al. (2010b). Antinociceptive activity of the essential oil of Zingiber zerumbet. Planta Med. 76 (2), 107-112. doi: $10.1055 / \mathrm{s}-0029-1185950$

Suzuki, R., Rahman, W., Hunt, S. P., and Dickenson, A. H. (2004a). Descending facilitatory control of mechanically evoked responses is enhanced in deep dorsal horn neurones following peripheral nerve injury. Brain Res. 1019 (1), 68-76. doi: 10.1016/j.brainres.2004.05.108

Suzuki, R., Rygh, L. J., and Dickenson, A. H. (2004b). Bad news from the brain: descending 5-HT pathways that control spinal pain processing. Trends Pharmacol. Sci. 25 (12), 613-617. doi: 10.1016/j.tips.2004.10.002

Svensson, T. H., Bunney, B. S., and Aghajanian, G. K. (1975). Inhibition of both noradrenergic and serotonergic neurons in brain by the alpha-adrenergic agonist clonidine. Brain Res. 92 (2), 291-306. doi: 10.1016/0006-8993(75)90276-0

Tang, Y.-P., Shimizu, E., Dube, G. R., Rampon, C., Kerchner, G. A., Zhuo, M., et al. (1999). Genetic enhancement of learning and memory in mice. Nature 401 (6748), 63-69. doi: 10.1038/43432

Tracey, I., and Mantyh, P. W. (2007). The cerebral signature for pain perception and its modulation. Neuron 55 (3), 377-391. doi: 10.1016/j.neuron.2007.07.012

Wang, H., Li, Y., Dun, L., Xu, Y., Jin, S., Du, J., et al. (2013). Antinociceptive effects of oxymatrine from Sophora flavescens, through regulation of NR2Bcontaining NMDA receptor-ERK/CREB signaling in a mice model of neuropathic pain. Phytomedicine 20 (11), 1039-1045. doi: 10.1016/ j.phymed.2013.04.012

Wei, F., Qiu, C.-S., Kim, S. J., Muglia, L., Maas, J. W., Pineda, V. V., et al. (2002). Genetic elimination of behavioral sensitization in mice lacking calmodulinstimulated adenylyl cyclases. Neuron 36 (4), 713-726. doi: 10.1016/S0896-6273 (02)01019-X

Wu, L.-J., Toyoda, H., Zhao, M.-G., Lee, Y.-S., Tang, J., Ko, S. W., et al. (2005). Upregulation of forebrain NMDA NR2B receptors contributes to behavioral sensitization after inflammation. J. Neurosci. 25 (48), 11107-11116. doi: 10.1523/jneurosci.1678-05.2005

Xu, M., Wei, H., Kontinen, V. K., Kalso, E., and Pertovaara, A. (2000). The dissociation of sedative from spinal antinociceptive effects following administration of a novel alpha-2-adrenoceptor agonist, MPV-2426, in the locus coeruleus in the rat. Acta Anaesthesiol Scand. 44 (6), 648-655. doi: 10.1034/j.1399-6576.2000.440604.x

Yalcin, I., Choucair-Jaafar, N., Benbouzid, M., Tessier, L. H., Muller, A., Hein, L., et al. (2009a). beta(2)-adrenoceptors are critical for antidepressant treatment of neuropathic pain. Ann. Neurol. 65 (2), 218-225. doi: 10.1002/ana.21542

Yalcin, I., Tessier, L. H., Petit-Demouliere, N., Doridot, S., Hein, L., FreundMercier, M. J., et al. (2009b). Beta2-adrenoceptors are essential for desipramine, venlafaxine or reboxetine action in neuropathic pain. Neurobiol. Dis. 33 (3), 386-394. doi: 10.1016/j.nbd.2008.11.003
Yamamoto, W., Sugiura, A., Nakazato-Imasato, E., and Kita, Y. (2008). Characterization of primary sensory neurons mediating static and dynamic allodynia in rat chronic constriction injury model. J. Pharm. Pharmacol. 60 (6), 717-722. doi: 10.1211/jpp.60.6.0006

Yeon, K. Y., Kim, S. A., Kim, Y. H., Lee, M. K., Ahn, D. K., Kim, H. J., et al. (2010). Curcumin produces an antihyperalgesic effect via antagonism of TRPV1. J. Dental Res. 89 (2), 170-174. doi: 10.1177/0022034509356169

Yogeeswari, P., Semwal, A., Mishra, R., and Sriram, D. (2009). Current approaches with the glutamatergic system as targets in the treatment of neuropathic pain. Expert Opin. Ther. Targets 13 (8), 925-943. doi: 10.1517/14728220903029210

Zhao, X., Xu, Y., Zhao, Q., Chen, C. R., Liu, A. M., and Huang, Z. L. (2012). Curcumin exerts antinociceptive effects in a mouse model of neuropathic pain: descending monoamine system and opioid receptors are differentially involved. Neuropharmacology 62 (2), 843-854. doi: 10.1016/ j.neuropharm.2011.08.050

Zhao, X., Wang, C., Zhang, J. F., Liu, L., Liu, A. M., Ma, Q., et al. (2014). Chronic curcumin treatment normalizes depression-like behaviors in mice with mononeuropathy: involvement of supraspinal serotonergic system and GABAA receptor. Psychopharmacology 231 (10), 2171-2187. doi: 10.1007/ s00213-013-3368-2

Zimmermann, M. (1983). Ethical guidelines for investigations of experimental pain in conscious animals. Pain 16 (2), 109-110. doi: 10.1016/0304-3959(83)90201-4

Zulazmi, N. A., Gopalsamy, B., Farouk, A. A., Sulaiman, M. R., Bharatham, B. H., and Perimal, E. K. (2015). Antiallodynic and antihyperalgesic effects of zerumbone on a mouse model of chronic constriction injury-induced neuropathic pain. Fitoterapia 105, 215-221. doi: 10.1016/j.fitote.2015.07.011

Zulazmi, N. A., Gopalsamy, B., Min, J. C., Farouk, A. A., Sulaiman, M. R., Bharatham, B. H., et al. (2017). Zerumbone alleviates neuropathic pain through the involvement of L-Arginine-Nitric Oxide-cGMP-K(+) ATP channel pathways in chronic constriction injury in mice model. Molecules 22 (4), 555. doi: $10.3390 /$ molecules 22040555

Zygmunt, P. M., Petersson, J., Andersson, D. A., Chuang, H., Sorgard, M., Di Marzo, V., et al. (1999). Vanilloid receptors on sensory nerves mediate the vasodilator action of anandamide. Nature 400 (6743), 452-457. doi: 10.1038/22761

Conflict of Interest: The authors declare that the research was conducted in the absence of any commercial or financial relationships that could be construed as a potential conflict of interest.

Copyright (c) 2020 Chia, Izham, Farouk, Sulaiman, Mustafa, Hutchinson and Perimal. This is an open-access article distributed under the terms of the Creative Commons Attribution License (CC BY). The use, distribution or reproduction in other forums is permitted, provided the original author(s) and the copyright owner(s) are credited and that the original publication in this journal is cited, in accordance with accepted academic practice. No use, distribution or reproduction is permitted which does not comply with these terms. 